\title{
Using SEEPS with a TRMM-Derived Climatology to Assess Global NWP Precipitation Forecast Skill
}

\author{
RACHEl C. NORTh, ${ }^{\mathrm{a}}$ MARION P. MitTermaier, ${ }^{\mathrm{a}}$ AND SEAN F. Milton ${ }^{\mathrm{a}}$ \\ ${ }^{\text {a }}$ Met Office, Exeter, United Kingdom
}

(Manuscript received 6 November 2020, in final form 20 October 2021)

\begin{abstract}
Monitoring precipitation forecast skill in global numerical weather prediction (NWP) models is an important yet challenging task. Rain gauges are inhomogeneously distributed, providing no information over large swathes of land and the oceans. Satellite-based products, on the other hand, provide near-global coverage at a resolution of $\sim 10-25 \mathrm{~km}$, but limitations on data quality (e.g., biases) must be accommodated. In this paper the stable equitable error in probability space (SEEPS) is computed using a precipitation climatology derived from the Tropical Rainfall Measuring Mission (TRMM) TMPA 3B42 V7 product and a gauge-based climatology and then applied to two global configurations of the Met Office Unified Model (UM). The representativeness and resolution effects on an aggregated SEEPS are explored by comparing the gauge scores, based on extracting the nearest model grid point, with those computed by upscaling the model values to the TRMM grid and extracting the TRMM grid point nearest the gauge location. The sampling effect is explored by comparing the aggregate SEEPS for this subset of $\sim 6000$ locations (dictated by the number of gauges available globally) with all land points within the TRMM region of $50^{\circ} \mathrm{N}$ and $50^{\circ} \mathrm{S}$. The forecast performance over the oceanic areas is compared with performance over land. While the SEEPS computed using the two different climatologies should never be expected to be identical, using the TRMM climatology provides a means of evaluating near-global precipitation using an internally consistent dataset in a climatologically consistent way.
\end{abstract}

KEYWORDS: Climatology; Satellite observations; Forecast verification/skill; Numerical weather prediction/forecasting; Model evaluation/performance; Rainfall

\section{Introduction}

Precipitation is a vital component of the global water cycle, in addition to being of direct relevance to the public. As an example, heavy precipitation and subsequent flooding can have drastic impacts on human activities, and accurate precipitation forecasts on time scales of several days ahead enables vulnerable communities to take action to protect themselves. A better understanding of precipitation forecast skill, diurnal cycle, and systematic errors could provide important pointers for continued model developments, leading to forecast improvements.

Land-sea contrasts and complex terrain are key factors affecting the spatial distribution of precipitation. They can act as foci for enhancing precipitation locally. Situations will arise where a coastal sea point is considered the nearest model grid point to a gauge location. Land and sea points in the model could have very different characteristics, with a sea point not being representative of what is happening just onshore at the gauge location. The model's view of the coast and complex terrain may be very different, and the view is resolution dependent. Fortunately, global numerical weather prediction (NWP) models are rapidly increasing in horizontal resolution, resolving more spatial detail as a result, with a better-defined model orography and coasts. However, precipitation in complex terrain, such as orographically enhanced precipitation is (still) not necessarily well forecast or well observed.

Increasing horizontal resolution has been a significant contributor to improvements in global NWP precipitation

\footnotetext{
Corresponding author: Rachel North, rachel.north@metoffice. gov.uk
}

forecast skill (e.g., Rodwell et al. 2010; Haiden et al. 2012). However, the scale gap between NWP model output and gauge point observations remains large. Verification of global models suffers both from representativeness issues and the double penalty (Mass et al. 2002; Rossa et al. 2008). This becomes particularly relevant for convective precipitation that is spatially discontinuous and temporally intermittent. Then, verification against gauges becomes particularly affected, whatever the model resolution is, because any precipitation has to fall directly over the gauge to be measurable.

It is especially for convective precipitation where the usefulness of remotely sensed gridded precipitation products has been demonstrated and the comparative disadvantages of gauges highlighted. Locally such products are often groundradar based, providing kilometer-scale precipitation rates with a temporal frequency on the order of minutes, but these do not provide global coverage. The launch of the Tropical Rainfall Measuring Mission (TRMM; Kummerow et al. 2000), and more recently the Global Precipitation Measurement mission (GPM; Hou et al. 2014; Skofronick-Jackson et al. 2017), has provided unprecedented spatial coverage on a "near global" scale, and although not with the same spatial or temporal footprint as ground-based radar rainfall products, it is sufficient for producing precipitation estimates at the subdaily scale.

Remotely sensed datasets do have a number of shortcomings, but many have been addressed by using multiple sensors. Gauge measurements are also far from error-free. Commonly used tipping-bucket gauges are subject to systematic errors (e.g., calibration, wind-induced undercatch, or evaporation losses) and random instrumental errors, all of which have been studied extensively (e.g., Humphrey et al. 1997; Habib 
et al. 1999; Ciach 2003; Køltzow et al. 2019). Gauges are also sparse in complex terrain and remote areas, generally providing an assessment of precipitation in areas close to civilization and easier terrain. Over land the distribution of rain gauges is highly variable. In some regions of the world there are few observations, and not just because there are none but because the exchange of observations between countries is politically sensitive and often has a monetary value. They are also unable to provide information about precipitation falling over the oceans, a critical part of the global water cycle. Using a gridded satellite-borne observation dataset can provide the ability to differentiate between NWP performance over sea and land.

NWP models provide a gridbox average. With increasing resolution, this average would appear to converge toward a point estimate, more like the measurement by a rain gauge. However, no matter how fine the resolution is, NWP produces precipitation values over a grid box. Gridded observation datasets merge radar and satellite retrievals to obtain a gridded product, which inherently addresses (some of) the representativeness issues, while providing an area-average precipitation estimate, similar to that of the NWP. Daily global datasets have been available for the climate community for some time, e.g., the Global Precipitation Climatology Project (GPCP; Huffman et al. 2001), but this is not available in near-real time and is too coarse for NWP. TRMM and now GPM provide much better spatial and temporal resolution that is more suited for NWP verification of daily precipitation accumulations (see section $3 \mathrm{a}$ ).

Rodwell et al. (2010) introduced the stable equitable error in probability space (SEEPS) score to account for the spatial variations in climatology. Each location can be verified in a climatologically consistent way, by using local climatology, derived from gauges. By accounting for the local climatology, scores can then also be aggregated safely and unambiguously, without incurring false skill (Hamill and Juras 2006). The utility of SEEPS has been recognized (Haiden et al. 2012; North et al. 2013) but its use has been limited due to the requirement of having a climatology derived from long records of rainfall at gauge locations. Even though gauge accumulations are exchanged via the World Meteorological Organization (WMO) Global Transfer System, an internal study for the WMO Commission for Basic Systems (CBS) showed that the four participating global modeling centers were unable to retrieve the same station dataset for a predefined period. As a result only individual station scores are exchanged (see appendix 2.2.34 of World Meteorological Organization 2019) so that aggregation over regions can be done carefully. The option of a gridded dataset, such as offered by TRMM and GPM, providing continuous "near global" coverage in space and time is rather compelling, and eliminates many of the issues that arise from using gauges, where each country's National Meteorological and Hydrological Service (NMHS) may have different protocols in place.

In this paper TRMM, GPM, and gauge data are used to verify daily precipitation forecasts from two versions of the Met Office Unified Model (UM) to explore the following aspects:

- How do the gauge- and TRMM-derived climatologies compare?
- How does SEEPS compare between being derived using gauge and TRMM pixels corresponding to gauge locations?

- What is the impact of spatial sampling on the score?

- How does SEEPS vary spatially on a grid, on daily and monthly time scales?

- What are the differences in forecast skill between the land and sea areas?

- How can SEEPS be used to compare model versions?

Section 2 describes SEEPS and how the method was amended for computation on a grid. Section 3 introduces and compares the gauge- and TRMM-derived climatologies. The model configurations that are compared in this study are described in section 4 . Results are presented in section 5 , followed by a discussion and concluding remarks in section 6 .

\section{Stable equitable error in probability space definition}

\section{a. Original definition}

SEEPS (Rodwell et al. 2010) was developed for monitoring of the precipitation forecast performance, while also providing some diagnostic (spatial and intensity) information to assist with the identification of model error. The score is designed to be as insensitive as possible to sampling uncertainty, and is equitable (see, e.g., Murphy and Winkler 1987; Gandin and Murphy 1992).

SEEPS is defined based on three categories: "dry,", "light," and "heavy" precipitation. The three-category SEEPS that has been used in Rodwell et al. (2010) and Haiden et al. (2012) is in essence the average of two Peirce skill scores (Peirce 1884), one assessing the rain-no-rain interface; the second differentiates between so-called heavy and light precipitation, based on the thresholds derived from the long-term gauge climatology.

The scoring matrix $s_{v, f}^{S}$ for SEEPS (as in Rodwell et al. 2010) is given by

$$
s_{v, f}^{S}=\frac{1}{2}\left\{\begin{array}{ccc}
0 & \frac{1}{1-p_{1}} & \frac{1}{p_{3}}+\frac{1}{1-p_{1}} \\
\frac{1}{p_{1}} & 0 & \frac{1}{p_{3}} \\
\frac{1}{p_{1}}+\frac{1}{1-p_{3}} & \frac{1}{1-p_{3}} & 0
\end{array}\right\}
$$

where the row corresponds to the forecast category $f$ and the column corresponds to the observed category $v$.

Here $p_{1}$ is the observed climatological probability of dry weather and $p_{2}$ and $p_{3}$ are the observed climatological probabilities of light and heavy precipitation, respectively, at a given observing site where $p_{1}+p_{2}+p_{3}=1$. The $p_{1}$ is set to the percentile at which the accumulation exceeds $0.2 \mathrm{~mm} \mathrm{day}^{-1}$. "Wet" days are divided in the ratio 2:1 with a fraction $p_{2}$ of all days being said to have light precipitation and a fraction $p_{3}$ $\left(p_{2} / 2\right)$ of all days said to have heavy precipitation. Hence, the threshold (in millimeters of precipitation) between the light and heavy categories depends on the local climatology. SEEPS at station $k$ is then calculated as an array inner-product of the scoring matrix and the contingency table of category pairs: 


$$
S_{k}=\sum_{v, f} \tilde{p}_{v, f} s_{v, f}^{S}
$$

where $\tilde{p}_{v, f}$ is an estimate of the joint probabilities and $s_{v, f}^{S}$ is the scoring matrix defined in Eq. (1).

To aggregate scores from individual gauge sites the station density must be accounted for. This is done using a Gaussian kernel; see Rodwell et al. (2010) for details. The reference angle $\alpha_{0}$ defines a length scale for which stations are approximately equidistant from each other. Rodwell et al. (2010) and Haiden et al. (2012) used a value of $0.75^{\circ}$ for $\alpha_{0}$, which is more specifically tuned to achieve approximately even station density over Europe.

By using local climatologies, SEEPS can be aggregated spatially and plotted as a time series. SEEPS is a measure of the forecast error: a perfect forecast yields to a SEEPS equal to 0 , and as the error grows SEEPS values grow larger; equitability constraints ensure that SEEPS ranges between 0 and 1 for time-averaged scores (Rodwell et al. 2010). SEEPS can be formulated as a skill score by plotting 1 - SEEPS to give a positively oriented measure of the forecast skill.

Because of the nature of SEEPS, components from individual errors in the contingency table can be extracted, e.g., forecast category is heavy when observed category is light, as used in Rodwell et al. (2010) and Haiden et al. (2012). These error categories provide insight into the behavior of the modeling system; errors can be described as being in "off by 1 " or "off by 2" categories, i.e., observed dry forecast light (ODFL) is an example of off-by-1 error whereas observed heavy forecast dry (OHFD) is an example of an off-by-2 error. In the subsequent sections, the following shorthand will be used: observed dry but forecast light (ODFL), observed dry but forecast heavy (ODFH), observed light but forecast dry (OLFD), observed light but forecast heavy (OLFH), observed heavy but forecast dry (OHFD), and observed heavy but forecast light (OHFL). Alternatively, rows or columns may also be collectively referred to as $\mathrm{OD}, \mathrm{OL}$, and $\mathrm{OH}$ and FD, FL, and $\mathrm{FH}$.

\section{b. Amended definition}

Given the use of a gridded observation dataset, any issues with respect to station network density disappear, with the effect that each grid square in a region will contribute equally to an aggregated score so that the process of aggregation is a simple one: dividing the cumulative score over the region by the number of grid points in the region, with the following caveat. Scores calculated from pixels with $p_{1}$ values outside the range of [0.1, 0.85], as suggested by Rodwell et al. (2010), should not be included in any weighted area scores to reduce uncertainty in area-mean scores, so the number of grid points in the aggregation region must be adjusted to remove those with $p_{1}$ values outside this range.

In our study we use the TRMM dataset $(\sim 25-\mathrm{km}$ resolution) for the climatology and the GPM $(\sim 10-\mathrm{km}$ resolution) as observation dataset against which the UM forecast ( $\sim 10-15-\mathrm{km}$ resolution) is verified. To enable comparison between point-based and gridded climatologies and scores, the two following separate procedures were performed for verifying against gauges and satellite (Fig. 1). Values at the nearest grid squares to the station locations for that date and time were extracted from the observed (in this instance GPM regridded onto the TRMM grid), forecast and climatology fields. These grid squares were then used to calculate SEEPS at the station locations (Fig. 1b) and treated in the same way as the gauge data (i.e., $p_{1}$ limits applied and station-density weighting applied). When verifying against satellite products, both the observed GPM field and UM forecasts were upscaled to the coarser TRMM grid (Fig. 1c), prior to selecting the nearest grid point to the station location. Note that, for gauge-derived results, the nearest grid point to the station was selected from the full-resolution forecast fields. Note also that if more than one station is located within a forecast or TRMM grid box (Fig. 1a), that grid box (and the score) could be compared with more than one station (Figs. 1b-d).

\section{Comparing the TRMM and gauge climatologies}

\section{a. TRMM and GPM overview}

TRMM was active between 1997 to 2015 and provides a long history for creating a climatology. Since 2015 GPM has replaced TRMM as the real-time product. Before comparing climatologies it is worth listing some of the findings with regard to the quality and differences between the two.

Uncertainties in the TRMM 3B42 V7 research grade (3B42) precipitation estimate (Huffman et al. 2010) have been well documented. Most studies evaluate 3B42 against either rain gauges or a gridded rain gauge analysis (Ebert et al. 2007; Roca et al. 2010; Chen et al. 2015; Bharti and Singh 2015). A review of satellite rainfall products by Maggioni et al. (2016) found that orography, seasonality, and local climatology are influential in terms of biases (relative to gauges) and detection. For semiarid regions and complex terrain precipitation is more likely to be missed. Lighter rainfall and snow are associated with larger biases. The former is due to the inability of sensors to discriminate when warm clouds are raining or not over relatively warm surfaces (see also Ebert et al. 2007; Chen et al. 2015; Maggioni et al. 2016). The latter is related to problems with the algorithm over frozen surfaces (Chen et al. 2015). In addition, there are problems in mountainous terrain with orographic enhancement not being resolved (Chen et al. 2013).

Yang and Nesbitt (2014) used 3B42 to characterize the statistical properties of tropical and subtropical daily precipitation in the band between $37.5^{\circ} \mathrm{N}$ and $37.5^{\circ} \mathrm{S}$. They found that $51.85 \%$ of rain came from convection and the remainder from stratiform clouds with variations in rainfall amounts between land and sea areas. The average convective, stratiform and total rain per day was respectively $1.300,1.272$, and $2.573 \mathrm{~mm}$ day $^{-1}$ over the ocean and respectively $1.22,0.97$, and $2.19 \mathrm{~mm}$ day $^{-1}$ over land. They showed that large rain intensity events are very important in terms of total precipitation, especially over land. They also found that rainfall missed by the TRMM Precipitation Radar was mostly light rain that has little effect 


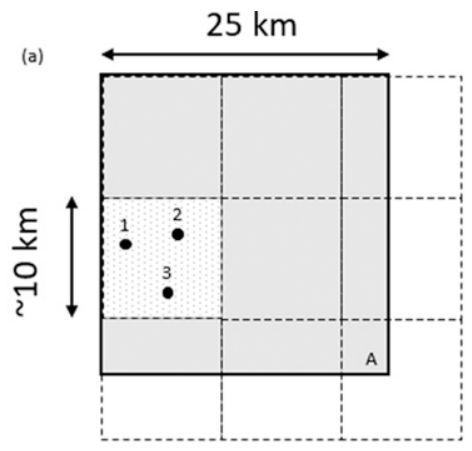

Schematic showing the resolution of the datasets involved.

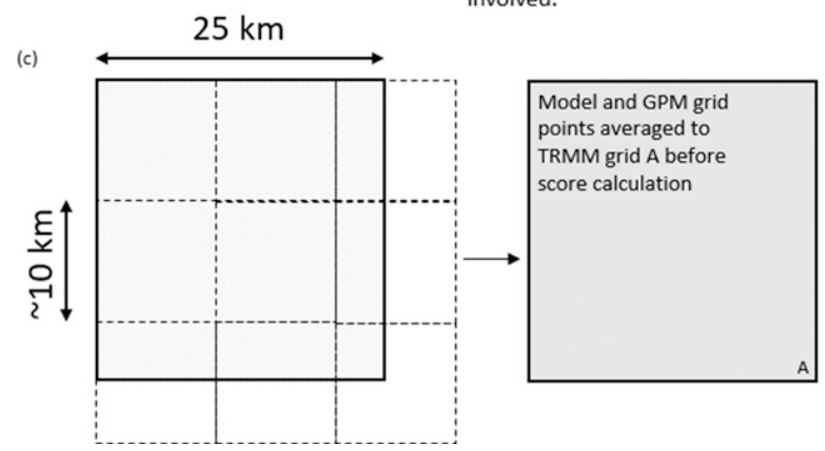

(b)

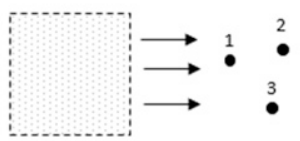

Same (nearest) model grid point precipitation accumulation is compared to three (different) gauge accumulations and a score computed for each gauge.

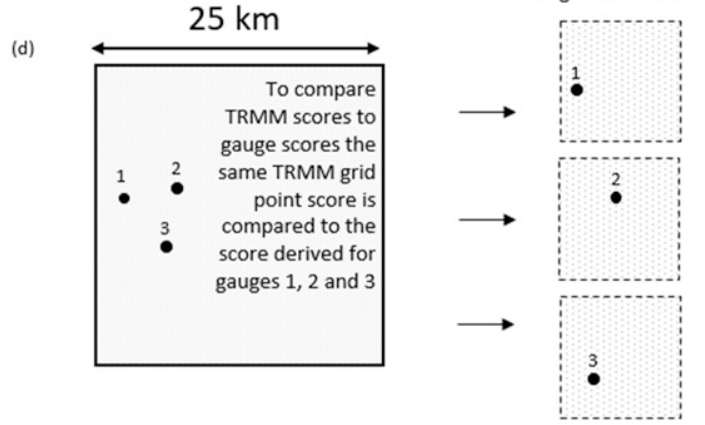

FIG. 1. Schematic to illustrate the mechanism used in producing SEEPS at gauge locations from the gridded datasets. (a) Observations (GPM IMERG V06B) are originally on an 10-km-resolution grid. Climatology fields (TRMM derived, from data from 1998 to 2015 ) are on an $\sim 25$-km-resolution grid. Sample station locations 1, 2, and 3 are all within one climatology grid box. (b) The same nearest model gridpoint accumulation is compared with the three (different) gauge amounts, and a score is computed for each gauge location. (c) Both the observations (GPM grid) and model grid are averaged to the TRMM grid before calculation of the SEEPS score. (d) The same TRMM gridpoint score is compared with the three (different) point scores derived at the gauge locations.

on the overall averages. They suggest that light rain could increase the total precipitation by about $10 \%$ and, if it were considered as a separate category, would decrease the observed convective and stratiform rain contributions by about $10 \%$ over the region that they considered.

Chen et al. (2015) looked at 3B42 over the United States from 2008 to 2010. Over the full period, the relative bias for mean daily precipitation across the whole region was small, only $-3.32 \%$. However, this masked large regional and seasonal variations. Daily precipitation underestimates in the colder seasons could be tied to detection and algorithm issues (regions with frozen surfaces are affected by underestimation, which is then compounded by detection issues over complex terrain). Relative biases, from comparison with a gridded gauge product, of up to $-36 \%$ were seen over the western United States in winter. Increased root-mean-square errors, of order 8-10 $\mathrm{mm} \mathrm{day}^{-1}$, against Stage IV radar data, were seen over the eastern United States. Here, light rain $\left(\leq 1 \mathrm{~mm} \mathrm{day}{ }^{-1}\right)$ was underestimated, likely as a result of detection issues with warm, shallow cloud.

Studies over the Sahel (Roca et al. 2010; Vogel et al. 2018) found that despite a slight dry bias relative to gauges, TRMM $3 \mathrm{~B} 42$ daily precipitation was the best dataset to use for comparing with gridded model precipitation forecasts.
For GPM, O et al. (2017) compared the half-hourly Early, Late, and Final Integrated Multisatellite Retrievals (IMERG) products over a dense gauge network in Austria over a 2-yr period and found the final product to be in best agreement with the gauges. Cui et al. (2020) looked at hourly mean and seasonal precipitation from IMERG over a 3-yr period across the central and eastern United States in the context of mesoscale convective systems. They found that IMERG showed a wet bias in the total precipitation, but the hourly means showed a dry bias relative to the radar-based Stage IV quantitative precipitation estimate.

$\mathrm{Xu}$ et al. (2017) evaluated the GPM IMERG and TRMM 3B42V7 daily rainfall over the southern Tibetan Plateau from March to October 2014, focusing on performance with respect to topography and precipitation intensity. They used over 500 rain gauges and showed that GPM is better than TRMM for all spatial scales and elevation ranges in terms of rainfall detection. TRMM had a false alarm ratio of $21 \%$ as compared with $14 \%$ for GPM. However, GPM missed more precipitation $(13 \%)$ than TRMM (9\%). They found that GPM tended to underestimate light rain days with $0-1 \mathrm{~mm} \mathrm{day}^{-1}$, whereas TRMM overestimated such days. GPM had better detection of rainfall between 0 and $5 \mathrm{~mm}$ day $^{-1}$, but neither had any 
ability to detect high-elevation precipitation above $4500 \mathrm{~m}$ (where there are unlikely to be many gauges). Zhang et al. (2018) found similar results over the Tibetan Plateau but were looking at diurnal variations. They found that while the half-hourly IMERG rainfall product can describe the diurnal variation there are timing differences for the occurrence of peak rainfall intensity, which is also overestimated. It would suggest that GPM might also have a light rain detection issue, which could lead to differences between using GPM or gauge data for verification.

Many of the satellite evaluation activities have been against ground-based radar rainfall estimates or gauges, neither of which are without errors of their own. Gauges, in particular, have been under scrutiny from the hydrological community for many decades. Gauges are often used as a benchmark for any remote-sensed rainfall estimates but are subject to many specific issues including wind speed-induced undercatch, errors for solid precipitation (hail, snow, melting, and condensation), evaporation, mechanical issues with tipping mechanisms, and issues related to the maintenance of equipment such as calibration. Cecinati et al. (2018) provide a useful summary of many of the issues. Good quality control will remove the impact of some of these errors, but more subtle issues may be harder to capture and account for. Using radar data as the comparator for evaluating satellite-based estimates suggests that at least the point-to-area representativeness error has been reduced but radar rainfall should also be treated as an estimate. A study by Smalley et al. (2014) showed that the Stage IV radar rainfall estimates over the United States were compromised with a lack of detection when temperatures approach or are below freezing. Older but relevant studies have shown that comparing radar-rainfall estimates with rain gauges can lead to errors up to $150 \%$. Villarini et al. (2008) and references therein provide a useful summary of radar-rainfall estimate errors relative to gauges.

To conclude, no precipitation datasets are perfect and error free (though we have attached this assumption to gauge measurements). Given the differences in sampling and construction, values will differ between point-based and areal estimates, providing similar but different climatologies. Both the gauge and TRMM derived climatologies are locally specific but with a different spatial definition of "local." It should be less a question of which one is right and which one is wrong but rather of noting that they are both right in their contextual setting; that is, they are approximations with error bounds that are generally unknown.

\section{b. Creating the TRMM climatology}

SEEPS requires locally relevant thresholds to determine the score at a point. These thresholds are calculated from long time series observation data, hereinafter referred to as a climatology. The climatology was constructed using daily composites of the TRMM 3B42v7 product from 1998 to 2015, inclusive [see TRMM (2011) for details]. Daily totals ending at 0000 UTC were created by accumulating the 3-hourly product.
At each TRMM grid point, distributions for each calendar month were calculated from daily precipitation totals for the period 1998-2015 and used to determine probabilities of being either dry, light or heavy precipitation. The dry/light threshold was fixed at $0.2 \mathrm{~mm}^{-1 a y}{ }^{-1}$, as per Rodwell et al. (2010), to facilitate a comparison of results, appreciating that this value may be too low for the satellite-based product. These climatologies were then used to define the SEEPS scoring matrices [see Eq. (1), section 2a] for each grid point, for the calculation of the area-aggregated SEEPS. This produced data on a grid of size $400 \times 1440$ points, covering a longitude range from $0^{\circ}$ to $360^{\circ}$ and a latitude range from $50^{\circ} \mathrm{S}$ to $50^{\circ} \mathrm{N}$.

Figure 2 shows spatial variations of $p_{1}$ values from TRMMderived climatologies in October and January (the central months of the seasons under study here). Yellow- and coralcolor areas denote regions in which $p_{1}$ values are outside the acceptable range $[0.1,0.85]$. The regions where $p_{1}$ is outside of these limits are surprisingly large and numerous, especially over the oceans. The values from the gauge climatology have been plotted on top. These are obvious in locations where either there is no gridded TRMM climatology value or where the TRMM-derived value and the gauge value differ (e.g., in January off the North Australian coast). The gauge climatology is the same as used by Rodwell et al. (2010) and has been subject to the same quality control methods described there.

Variations in the size of the areas covered by these masked $p_{1}$ (in coral and yellow) are seen between Figs. $2 \mathrm{a}$ and $2 \mathrm{~b}$. These size fluctuations affect the number of grid points available for calculation (and aggregation) of SEEPS. Note that most of the masked area is due to having a $p_{1}$ value greater than the 0.85 upper threshold (very dry locations). Very few grid points in the domain have $p_{1}<0.1$ (very wet). As described earlier, seasonality has an impact and will determine whether a region is masked from results (e.g., Australia or India). As a result, it is sensible to look at whether the geographical area under consideration will be fully masked due to climatology restrictions before calculating scores for subsequent analysis.

With a scatterplot of TRMM- and gauge-derived $p_{1}$ values at gauge locations, Fig. 3a suggests that there is less agreement between the gauge and TRMM values at the lower $p_{1}$ values (wetter locations). For drier locations (higher $p_{1}$ values) the gauge and TRMM values are more consistent, although the TRMM-derived thresholds appear higher than gauge-derived values (especially for $p_{1}>0.6$ ) in agreement with the literature cited in section $3 a$. Figure $3 b$ contains the scatterplot for the light-heavy threshold, $t_{2}$, values. For points within 1 standard deviation of the mean, this shows that $t_{2}$ is more likely to be higher in the TRMM climatology than in the gauge climatology. The points beyond one standard deviation from the mean show that there are some gauges with a much wetter distribution than TRMM. These locations could indicate a quality control issue with the station data used for the climatology. Figures $3 c$ and $3 d$ map the points shown in Figs. $3 \mathrm{a}$ and $3 \mathrm{~b}$. These maps indicate where the station observations differ from the satellite-derived values and can indicate issues with the gauge climatology values. 
(a) October

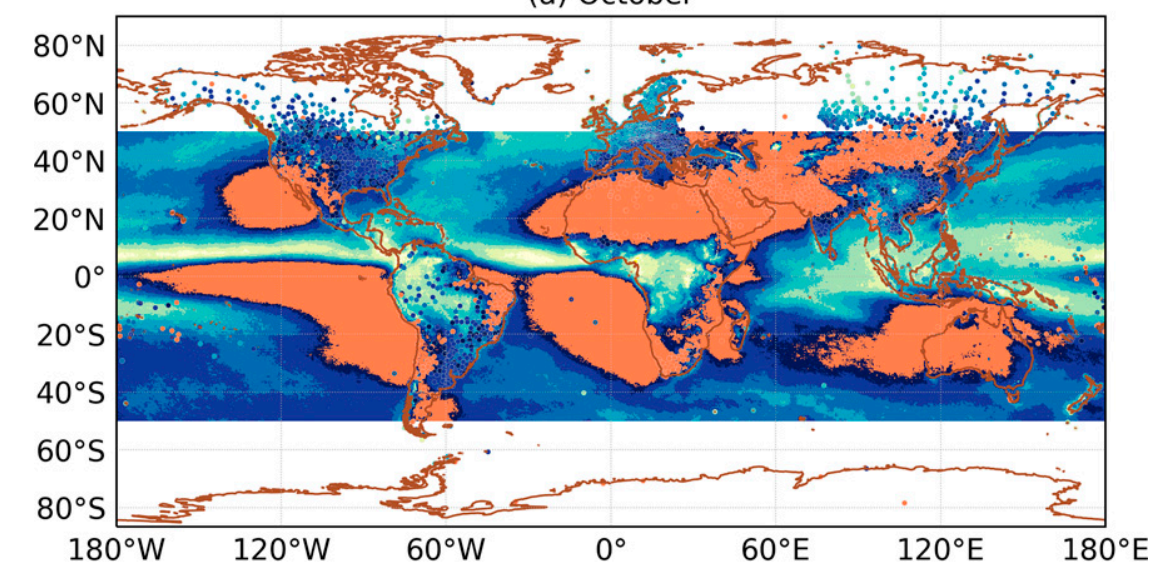

(b) January

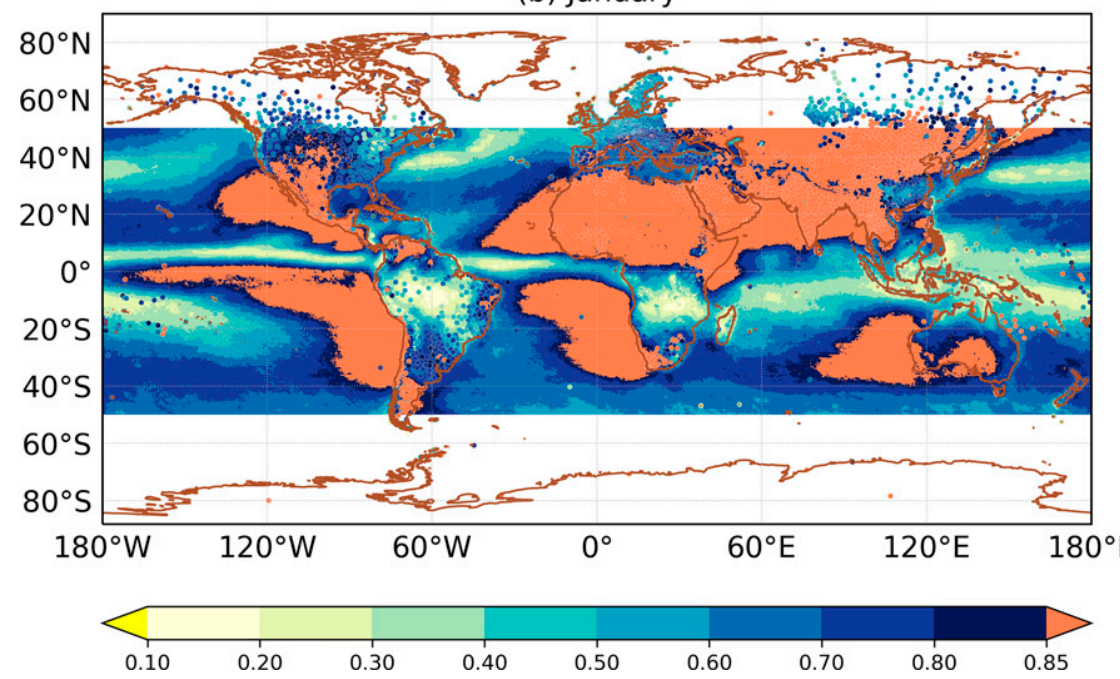

FIG. 2. Maps showing the magnitude of $p_{1}$, the probability of being dry, given the physical threshold of $0.2 \mathrm{~mm}^{-1 a y}{ }^{-1}$ to define the boundary between the "dry" and "light" precipitation for (a) October and (b) January for the TRMM climatology. Gauge climatology values are overplotted with the same color scale. See the text for further detail.

Figure 4 shows daily distributions for a sample of locations around the globe from the September climatology fields to illustrate distributions at several locations. Figure 4 a shows distributions resulting for three different types of grid point: (i) a wet grid point, (ii) a typical grid point, and (iii) a dry grid point. The first, with a low probability of being dry, shows a steep ramp-up in the daily accumulation between 1 and $10 \mathrm{~mm}$ day $^{-1}$ with an associated jump in the base rate from $\sim 0.2$ to $\sim 0.85$. The more typical continental midlatitude grid point has less very light rain and a higher threshold of rain-no rain. The driest location has a $p_{1}$ value of 0.99 with a few rain days captured in the tail with the maximum of less than $10 \mathrm{~mm}$ $\mathrm{day}^{-1}$. These different distributions illustrate why the thresholds between light and heavy precipitation vary so much.

Figure $4 \mathrm{~b}$ compares the gauge-derived distributions with the TRMM-derived ones at three sites: (i) Changi (48698) in Singapore, a "Maritime Continent" land grid point, (ii) Roissy
(7157), France (a fairly typical midlatitude point), and (iii) Flores (8501), on the Azores, which is likely to be a sea point in most global models. The distributions at Changi appear to be very well matched, especially at the lower and upper end of the distribution, though there are differences in the midranges between 1 and $10 \mathrm{~mm}$ day $^{-1}$. There are much larger differences for the other locations with the TRMM climatologies missing many lower accumulations below $1 \mathrm{~mm} \mathrm{day}^{-1}$. Roissy appears to have good agreement above $1 \mathrm{~mm}$ day $^{-1}$. Flores appears to have a very different distribution, though they do appear to converge in the upper tail. It is likely that the $t_{2}$ values are quite different between the two climatologies and this could translate to differences in the scores, i.e., one should not expect that the gauge- and TRMM-GPM-based scores will be the same. As will be shown in section $5 \mathrm{~b}$ the biggest differences in scores relate to error contributions from light precipitation, whether convective or stratiform in nature. 
(a)

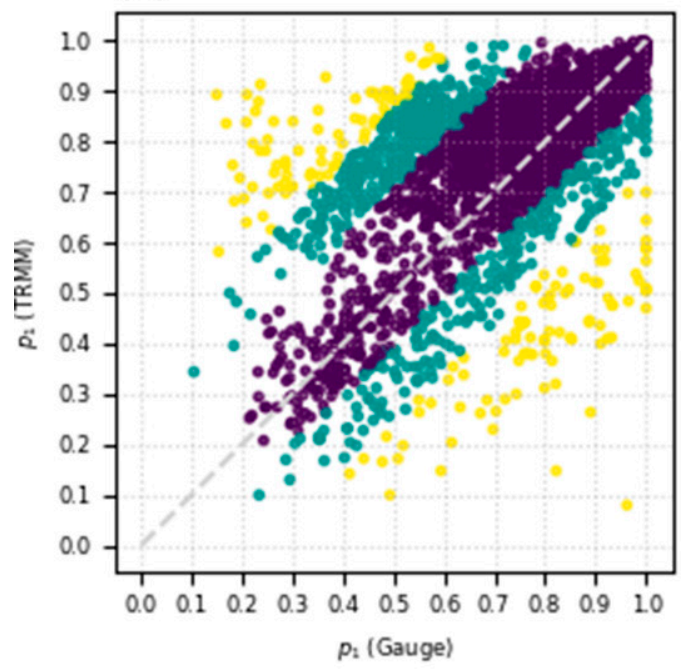

(b)

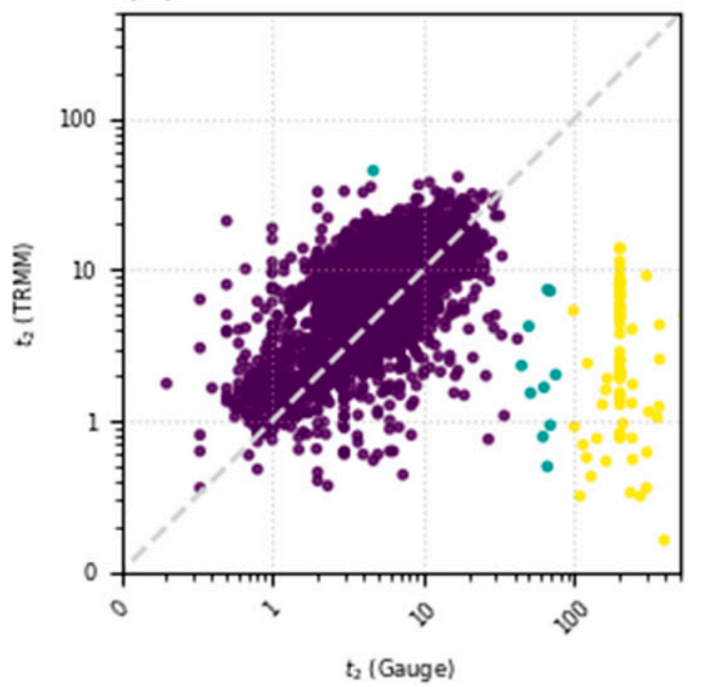

(c)

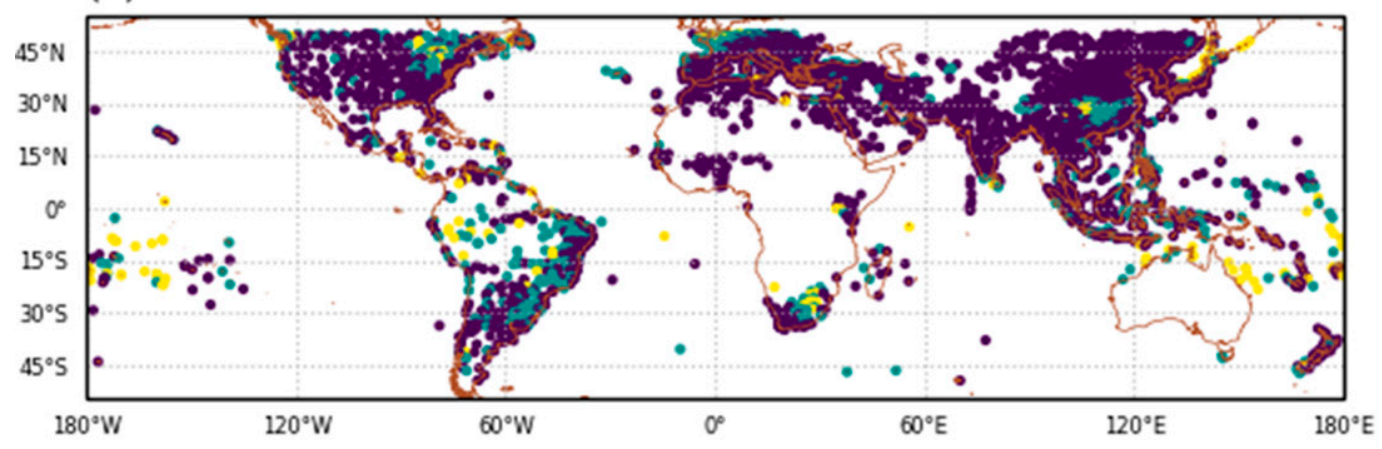

(d)

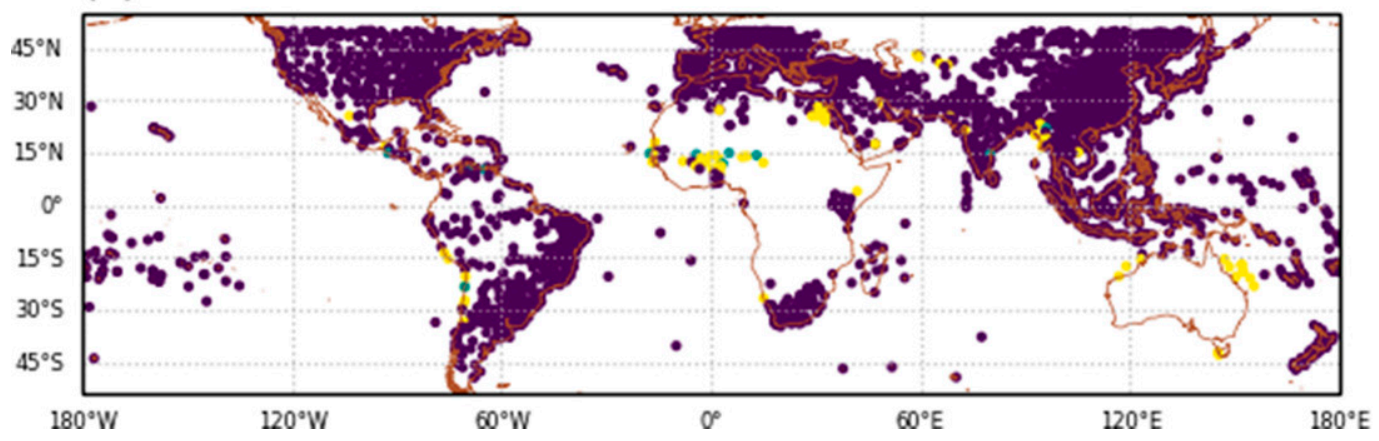

FIG. 3. Scatterplots comparing values from the daily TRMM climatology with those from the gauge observations in January for (a) $p_{1}$ and (b) the light-heavy precipitation threshold $t_{2}(\mathrm{~mm})$. TRMM-derived values are extracted from the nearest grid point to gauge station locations, which are themselves restricted to within the coverage of the TRMM grid (i.e., $\pm 50^{\circ}$ latitude). Points are colored according to their distance from the mean. Purple points are within 1 standard deviation (std dev), turquoise points are within 2 std dev, and yellow points are within 3 std dev. Maps of the station locations, colored also according to their distance from the mean, are provided for (c) $p_{1}$ and (d) $t_{2}$.

TRMM may be missing this precipitation or underestimating it, though not all the time or everywhere.

Figure 5 shows the TRMM-derived $t_{2}$ light-heavy threshold across the globe, for the midpoint of each season. The threshold from the gauge climatology is overplotted. The gauge climatology appears to yield higher thresholds in several regions; notably over northern and central Africa and off the coast of northern Australia, though the latter is due to these 

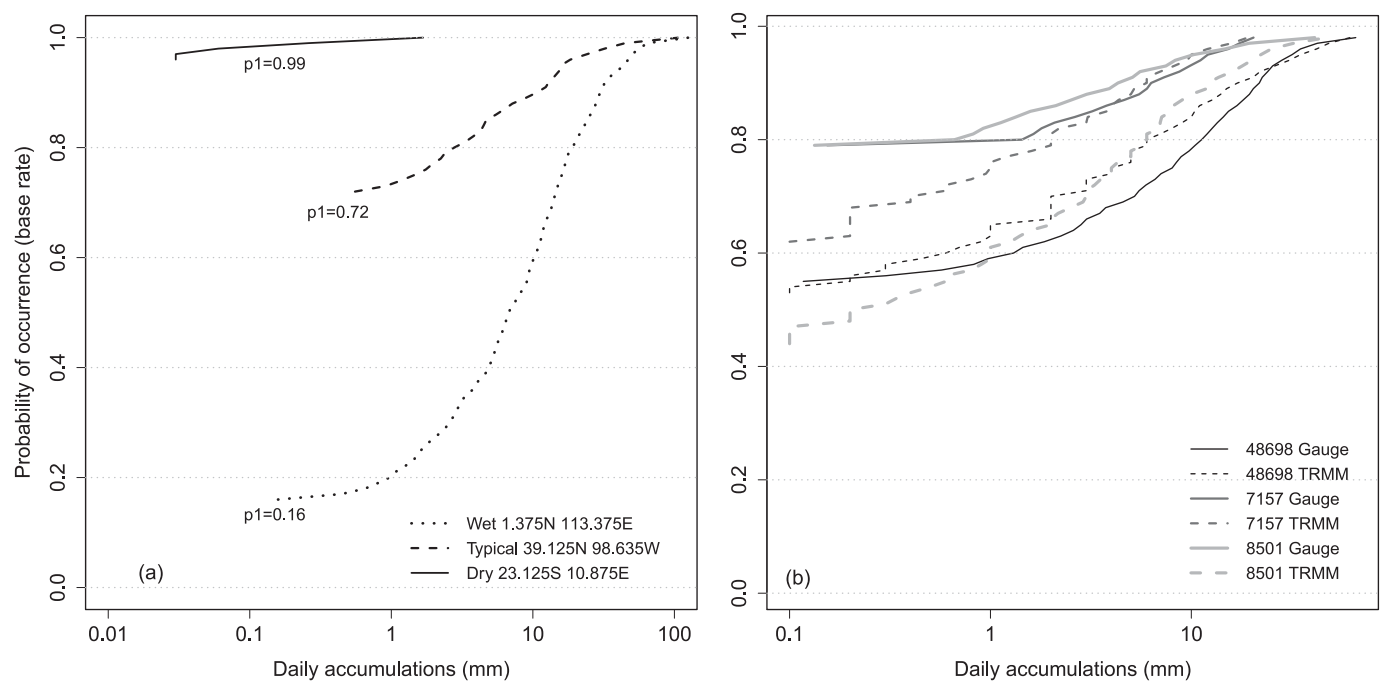

FIG. 4. (a) Climatological distributions comparison derived from TRMM showing the differences between "dry," "normal," and "wet" regions. Sample distributions are from the September climatology. Locations are drawn from the stratocumulus region of the southeastern Atlantic Ocean (off the African coast) (dry), the northeastern United States (typical), and Borneo in the Maritime Continent (wet). The $p_{1}$ value corresponds to the percentile at which the accumulation exceeds $0.2 \mathrm{~mm}$ day $^{-1}$. (b) Climatological distributions comparison comparing gauge-derived and TRMM-based distributions at a selection of gauge locations: Changi International airport (48698), Roissy (7157), and Flores (8501). Note the logarithmic $x$ axis.

locations having no data in the climatology files (100th percentile value is zero), meaning that a gauge-based SEEPS cannot be evaluated at these stations. The gauge climatologies have been plotted as supplied (by ECMWF 2015). In practice, this means there will be stations included on these maps that will not be considered in score calculations. The TRMM climatologies provide, in broad terms, a spatially smoothly varying climatology that is ideal for verifying forecasts over larger regions, with homogeneous spatial density (sampling).

The previous section highlighted the fact that TRMM and GPM probably underestimate light precipitation, though not always, all the time or everywhere. There are studies that show there may be deficiencies in semiarid regions and in complex terrain, especially at high altitudes. There are also studies that suggest that the presence of snow and freezing temperatures affect the accuracy of TRMM and GPM rainfall estimates. Many of the semiarid locations are dealt with in SEEPS through the $p_{1}$ constraint, which ensures that these locations are automatically excluded when the need arises. Equally many locations with considerable elevation-for example, the Tibetan Plateau-are also excluded during dry periods. The TRMM geographical extent limits the coverage to predominantly temperate latitudes where snow is confined to relatively small portions of the coverage. Nevertheless, further action is likely to be needed to refine locations that need to be masked out when aggregating SEEPS in space. We address the question of sensitivity of the SEEPS score to points like these in section $5 \mathrm{~b}$.

The TRMM climatology is used here because it provides near-global coverage, but in practical terms, any gridded climatology could be used, and it need not be global; that is, the focus could be regional if desired. The only requirement is that it is produced from a long-enough historical record with acceptable quality control, to provide a reasonable representation of the climate. This could include ground-radar-based climatologies, merged radar-gauge or gauge-only products, and even reanalyses. All of these data sources will provide different climatologies for the same location with observation uncertainty bounds that are generally not known.

\section{Model overview}

The Met Office Unified Model is designed for use in both weather and climate applications. It is a nonhydrostatic, semiimplicit, semi-Lagrangian, gridpoint model that is configured in the global deterministic version to use 70 vertical levels, which are terrain-following near the surface. A number of processes are parameterized, such as shortwave and longwave radiation (Edwards and Slingo 1996), mixed-phase cloud (Wilson and Ballard 1999), boundary layer processes (Lock et al. 2000), and cloud via the "PC2" scheme (Wilson et al. 2008). Parameterized convection is described by Gregory and Rowntree (1990). Current configurations use the "Even Newer Dynamics for General Atmospheric Modelling of the Environment (ENDGame; Wood et al. 2013). The global system uses hybrid data assimilation (DA) described by Clayton et al. (2012).

In this study two configurations are compared. The operational (GA6.1) configuration is a deterministic N1280 resolution model $(\sim 11 \mathrm{~km}$ at midlatitudes) with 70 vertical levels (referred to here as GA6.1) and is described by Walters et al. (2017). The other configuration is an early candidate for the Global Atmosphere (GA) release (a prototype GA8 configuration, referred to here as GA8P), at the same horizontal and 

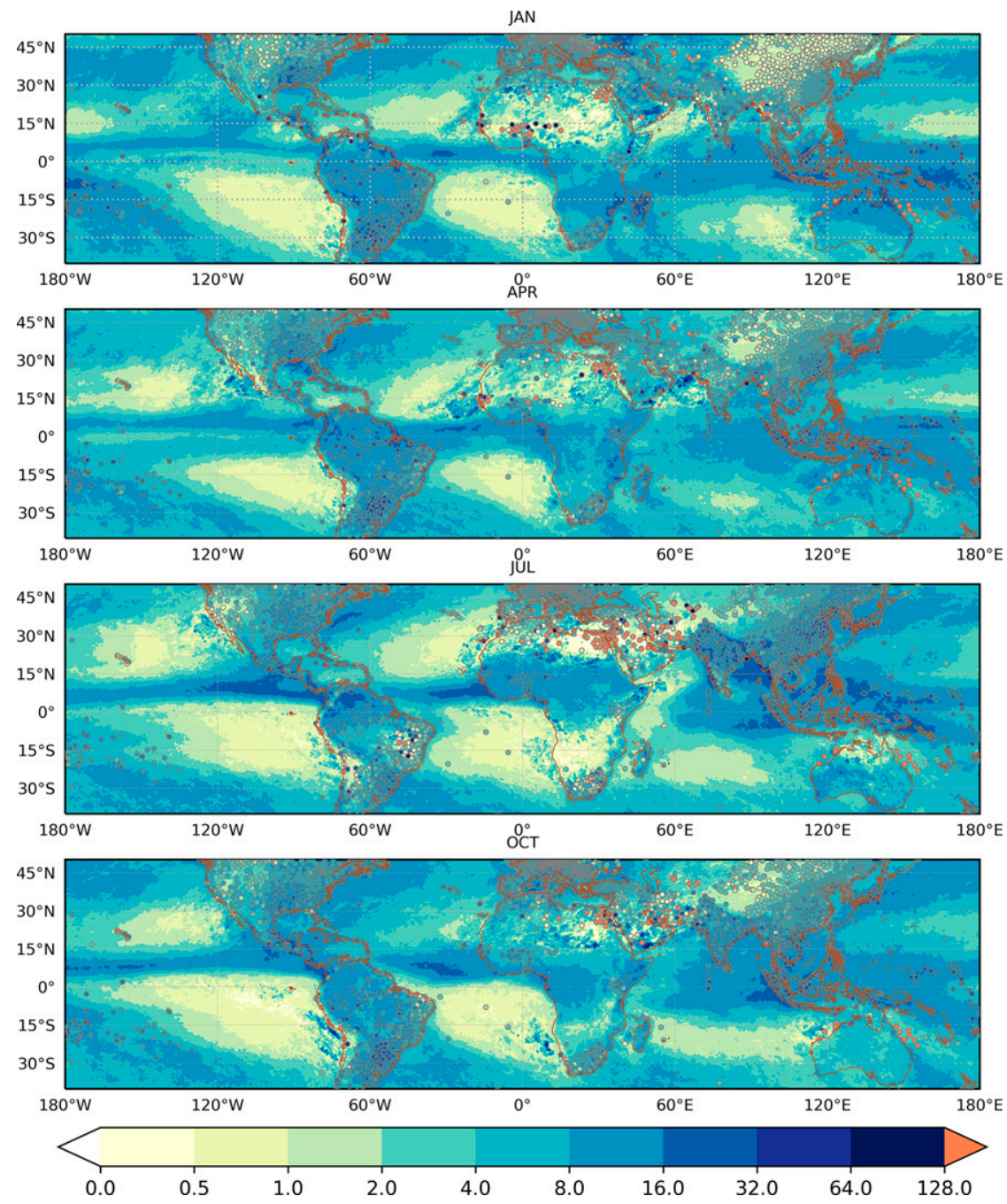

FIG. 5. Maps showing the magnitude of $t_{2}$, the boundary between the "light" and "heavy" precipitation categories. Gauge climatology values are overplotted as circular symbols with the same color scale, edged with a gray border. The gauge climatology seems to be considerably wetter for a number of geographical clusters. Two persistent clusters exist off the northwestern and northeastern coasts of Australia. These are in fact anomalies in the gauge climatology, where in reality these locations have no data, and so a gauge-based SEEPS cannot be evaluated here.

vertical resolutions. It has been run with no direct DA, with each forecast being initialized using the operational analysis, so that the forecast is indirectly benefitting from the operational hybrid DA. The primary science difference between the configurations is the treatment of convective precipitation. GA8P includes a prognostic tracer that controls the entrainment rate in the convection scheme, where initially entrainment is high, so any convective event will entrain large amounts of environmental air. This suppresses buoyancy and should delay initiation. As this convection rises, the prognostic is set in the levels that convection has reached, so that at the next time step the entrainment rate is much lower in the locations and levels where convection had previously reached. Convection can then pass through these levels easily, allowing it to develop higher on the subsequent time step (see Willett and Whitall 2017). This prognostic entrainment is expected to lead to improvements in the diurnal cycle of convective precipitation.

Daily precipitation from the 0000 UTC initializations of the GA6.1 and GA8P configurations are compared for the period from August 2018 to February 2019. Forecast accumulations from Day $1(0-24 \mathrm{~h})$ to Day $6(120-144 \mathrm{~h})$ are compared with 24-h totals derived from V06B GPM IMERG Final products that are valid for the same time.

\section{Results}

\section{a. Diagnosing model errors with spatial maps}

A useful by-product of the SEEPS calculation is the ability to create spatial contiguous maps showing the error components 

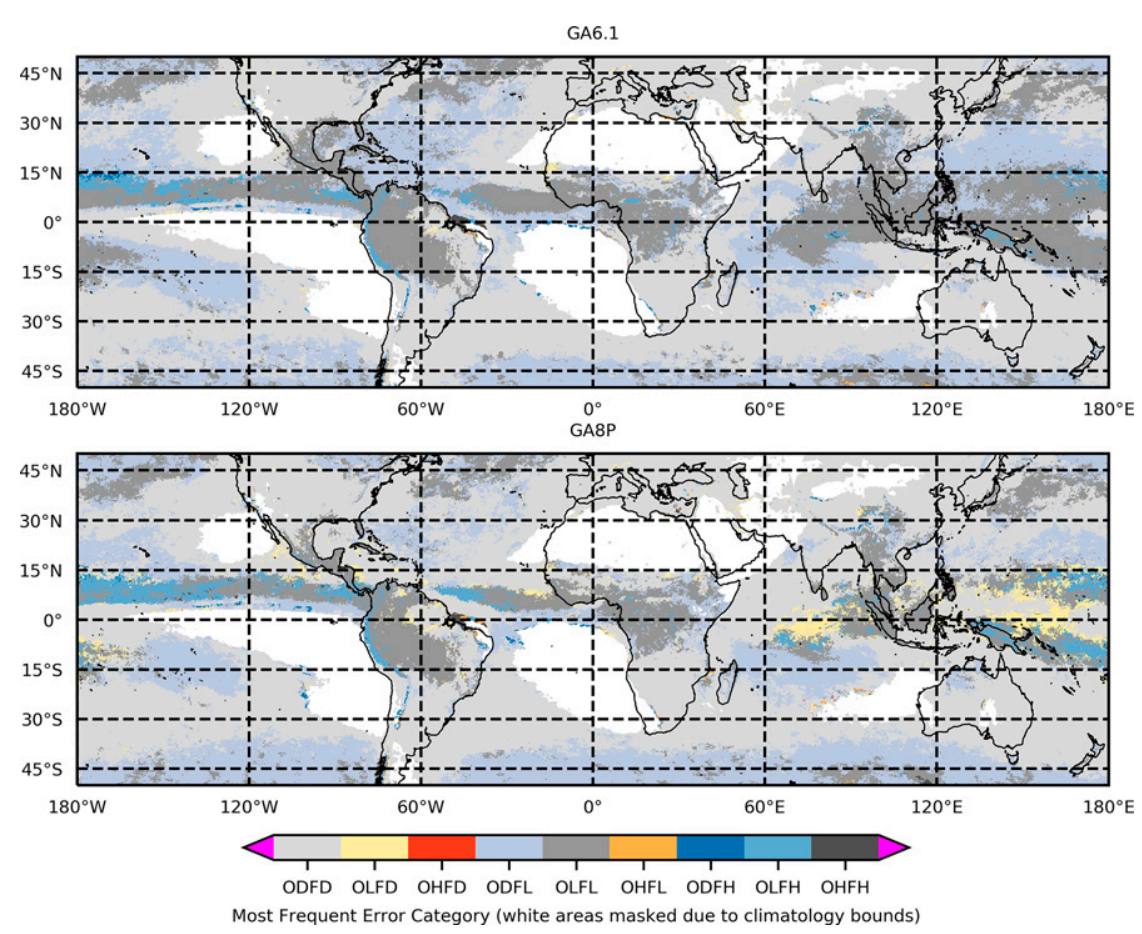

FIG. 6. Maps showing the most frequent error category for day 6 at a particular TRMM grid point in season September- November 2018. Errors are formulated in terms of the dry (D), light $(\mathrm{L})$, and heavy $(\mathrm{H})$ classification of observed $(\mathrm{O})$ and forecast $(\mathrm{F})$ precipitation, respectively (e.g., the category labeled OHFL on the legend is observed heavy but forecast light). Gray shades represent correctly forecast categories. Lighter shades represent the off-by-1-category errors, whereas stronger shades represent the off-by-2-category errors.

contributing to SEEPS at a given grid point on a particular date and time, from a particular forecast lead time. Determining the frequency of occurrence over time of each error category provides a method to diagnose systematic biases in the forecasting of daily precipitation accumulations at locations around the globe.

Figure 6 shows a seasonal analysis of the error category with the highest frequency from the day 6 forecasts during the season studied (September to November 2018). It shows the most frequently occurring category in this season for the GA6.1 model (top) and the GA8P configuration (bottom). White regions depict areas that are masked by the climatology limits used ( $\left.p_{1} \in[0.1,0.85]\right)$ when subsequently calculating the SEEPS scores.

Figure 6 shows that GA8P (bottom panel) has greatly improved the ODFL error (lightest blue), often described as the "overforecasting of drizzle" problem, which is present in the GA6.1 field (top panel), especially in the maritime areas south of India, in the Pacific Ocean, and in the North Atlantic Ocean basin. However, this has increased the prevalence of the OLFD category in that region, south of India, and to the east of the Maritime Continent. In the latter area, more frequent OLFH errors also now appear.

There appear to be instances of prevalent OLFH errors in areas of high orography (e.g., along the Andes), in both model versions and this may be more related to known deficiencies of the GPM and TRMM over high orography (missing precipitation). In addition, GA8P appears to have increased the spatial spread of OLFH in the tropical Pacific. It is reassuring to see that the off-by-2 category errors (ODFH and OHFD) are rare and that large parts of the global domain show the most common category is correct.

Temporally aggregated SEEPS for daily precipitation can be plotted for each TRMM grid point to create maps illustrating spatial variation in forecast performance. Figure 7 shows monthly-average SEEPS for October 2018 for GA8P (top) and GA6.1 (middle) and the difference between the two (bottom) at lead times of 1,3 , and 6 days. White areas indicate masked grid points, as before. Some of the largest (worst) scores are along the edges of these $p_{1}$-masked regions, highlighting areas of persistent larger SEEPS. SEEPS values increase (forecasts get worse) with lead time (from left to right along columns) in Fig. 7, expected behavior as a score will degrade with lead time. Quantitatively there are signs that GA8P has a positive impact (score reduction) in the tropics and especially over the oceans, supporting what is seen in Fig. 6; something that a gauge-based (land-only) SEEPS would not show. This could be linked to improved modeling of the enhanced convergence and associated convection in the area at the time (see, e.g., Climate Prediction Center 2020).

This demonstrates one of the great strengths of using a gridded climatology, since it enables identification of locations where performance is ambiguous, which can then be the focus 

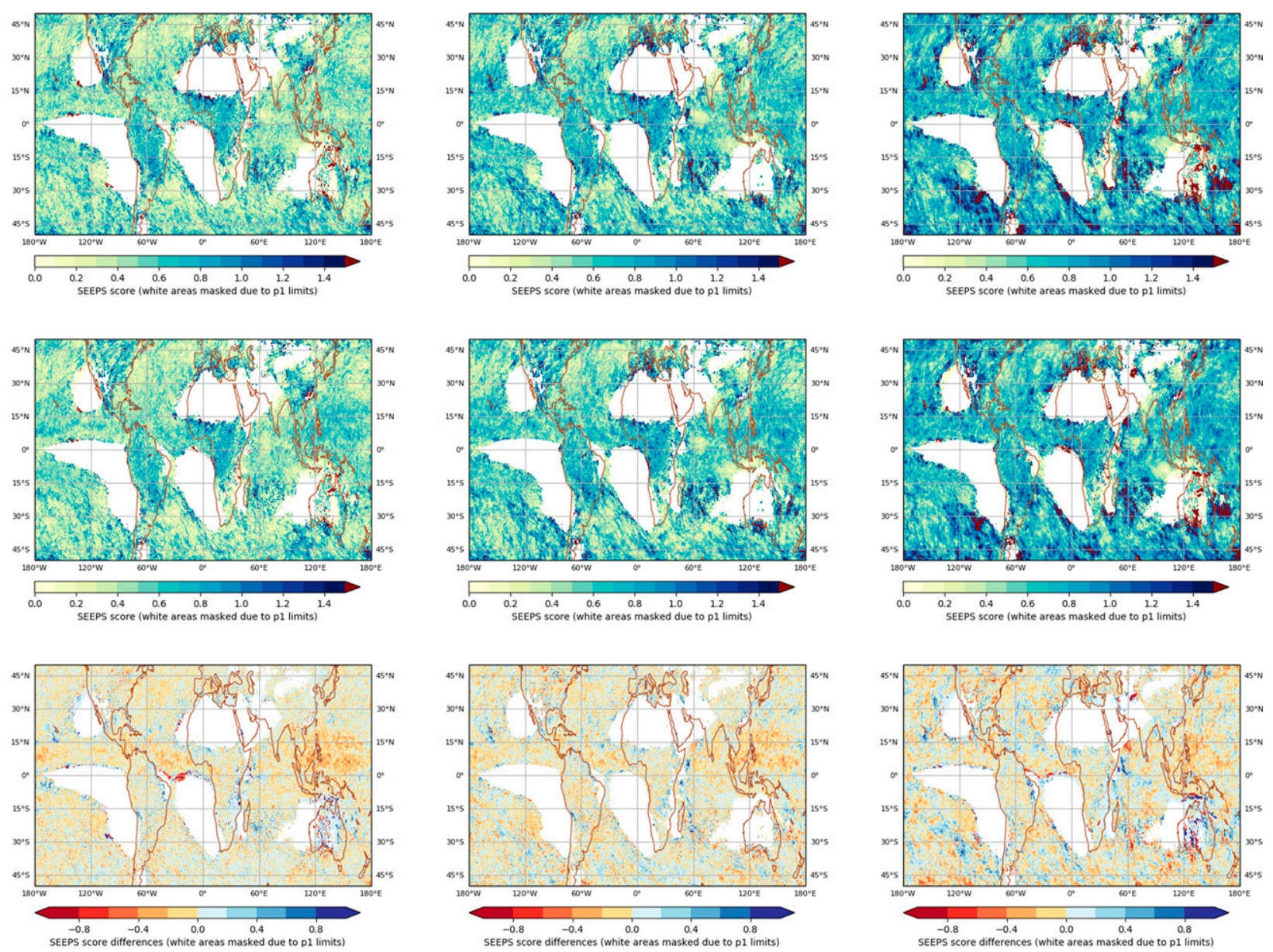

FIG. 7. Monthly average SEEPS for October 2018 at different lead times of (left) day 1, (center) day 3, and (right) day 6 for the (top) GA8P trial and (middle) GA6.1 operational model, and (bottom) the difference between the two (trial - operational). For the difference fields, red shades imply that GA8P is better and blue shades mean that GA8P is worse. Points for which SEEPS exceeds 1.0 imply consistently poor forecasts at those locations.

of future investigation. Sometimes these are model-related systematic problems, but often they relate to observation issues. The spatial view of performance assists in identifying locations that potentially should be eliminated for the purpose of spatially aggregating the scores over regions.

The difference pattern is set up early, within day 1 , and changes little with lead time. The edges of $p_{1}$-masked regions show some of the biggest SEEPS differences with orange/red regions indicating that $\mathrm{GA} 8 \mathrm{P}$ is better than GA6.1. Blue regions indicate GA6.1 is better than GA8P. A large proportion of these errors appear to be situated at the westward extent of the dry regions. This suggests the GA8P model struggles to get the geographical boundary between the dry and not-so-dry climatic regimes in the right place (e.g., Sahel), and this is already apparent on day 1 of the forecast.

\section{b. SEEPS components for GA6.1 and GA8P}

SEEPS can be aggregated over specific subregions of the globe (e.g., Rodwell et al. 2010); three regions have been chosen to show here. First, global scores are shown in this section, to illustrate the wider monitoring capabilities when produced on a map, and to illustrate bulk score properties and the ability to differentiate between land and sea. For the regional focus, the tropics and the WMO's CBS-defined region for North America (restricted to latitudes falling within the limits of the TRMM grid) are presented. The tropics has been selected because here there are relatively few gauges with a large proportion of sea points, where the TRMM grid provides a large increase in sample size. Moreover, it is in the tropics where we may expect to see more differences in the precipitation fields from the two model configurations that are being compared (given the physics changes and where they will likely have the most impact). North America has been selected because of the relatively high spatial density of gauge data, which facilitates a more direct comparison of the gauge results versus TRMM results and is largely land based. The North America domain is largely land-based and represents a region where continental subtropical and midlatitude convection is prevalent. The 
upscaling of the forecast and the use of a gridded precipitation product should provide improved sampling, a reduction in the impact of small spatial displacement errors, and a tool for diagnosing of the impact of the representativeness.

While an aggregated SEEPS is useful, one of its most convenient aspects is the ability to decompose the score to further understand the main sources of error and, in this case, where the differences between model versions are coming from. SEEPS components can be displayed as 3-by-3 or "9-up" plots (e.g., see Rodwell et al. 2011; North et al. 2013). The diagonal panels (shown in Figs. 8-13) show the forecast and observed frequencies for each category (i.e., assess the frequency bias). On either side of the diagonal, the errors are related to off-by-1 or off-by-2 categories, as described previously. Note that observed categories go along columns and forecast categories go along rows. The shorthand described in section 2 will be used here.

From the maps shown in Fig. 7 a spatial and temporal aggregate of daily precipitation scores (using the $p_{1}$ constraints) over all points (or a predefined region) and days can be computed. Figure 8 introduces results comparing GA8P with GA6.1 globally, for sea points (Fig. 8a) and land points (Fig. 8b), including all grid points that meet the $p_{1}$ criteria and are not masked due to being rejected from the original observed or forecast fields. These score aggregates are over the whole study period from August 2018-February 2019 (inclusive) and provide the means of evaluating performance also over the oceans in a stable, statistically robust new way to assess model performance, which can help to guide future model development beyond the traditional land-based gauge-only verification.

As SEEPS is an error score, a smaller value is better. Therefore, if the score difference is positive or negative the GA8P forecasts are respectively worse or better. Over sea areas, Fig. 8a shows that the differences between GA8P and GA6.1 are small, though significant, with an improvement in GA8P for day 1, but a degradation at longer lead times. SEEPS over land shown in Fig. 8b shows score differences are small but significantly worse in GA8P for all lead times.

Aggregated scores are decomposed and the results for sea points are shown in Fig. 8c. For the diagonal panels, the observation frequencies should be the same when the source of the observations is identical but will not be so when comparing land and sea points, say, or when comparing TRMM-derived scores at gauge grid points with actual gauge results. Observed frequency of occurrences (dashed lines) in the diagonal panels of Fig. 8c are overlaid, as expected since they are using the same observations. The forecasts underpredict the frequency of dry days (improved in GA8P). They overpredict the frequency of light precipitation (also improved in GA8P). Heavy precipitation is predicted too frequently, but here there is no difference in the model configurations. GA8P has therefore moved some of the light precipitation into the dry category. Figure $8 \mathrm{~d}$ shows the decomposition of the land-only SEEPS is broadly similar. A difference from the sea is seen in the heavy category (bottom-right panel) at early lead times where the forecast frequencies are increased (worse) in GA8P.
The main improvement for GA8P comes in the FL categories (middle row of both Figs. 8c and 8d). OHFL (missed heavy, middle-right panel) events contribute a larger part to the score over the land than sea, but in both cases is slightly improved in GA8P. Light false alarms (ODFL) are seen less over land and are also improved in GA8P. Heavy false alarms increase with lead time (ODFH, OLFH) especially over the sea, and GA8P does not improve this. However, some spurious heavy rain over the sea at early lead times does appear to have been removed (Fig. 8c, bottom left). GA8P appears to have increased misses (errors when the forecasts have no rain, FD, top row in both Figs. $8 \mathrm{c}$ and $8 \mathrm{~d}$ ), indicating that perhaps too much rain has been removed.

\section{1) LAND-SEA DIFFERENCES}

Figure 9 compares SEEPS calculated for GA6.1 for land points with those for sea points (looking at the land-sea split) to see what impact the sea points have on the overall score and whether it can be said that precipitation forecasts over the sea are better or worse than over land. As before, scores are computed using the TRMM climatology over all land grid points (except those masked as previously explained) against results from using only valid sea points over the 7-month period.

Figure 9a shows the area-aggregated SEEPS differences for the globe. Scores from land points are significantly worse than those from sea points, with the signal persisting to longer lead times. Only day 6 forecasts have small, nonsignificant differences.

Figure $9 \mathrm{~b}$ provides a decomposition of the score in Fig. 9a. The top-left panel (ODFD) shows that the forecast underestimates the dry frequencies, with greater discrepancies over the ocean; the observed frequency of dry sea points (dashed) is marginally larger than for land points (solid), and the forecast frequency of dry sea points (dotdashed) is marginally smaller than for land points (dotted). In the middle panel (OLFL), the forecast overestimates the light precipitation, more dramatically so over ocean; the occurrence of forecast light precipitation switches at day 2, with a higher frequency over land for day 1 , and a higher frequency over ocean beyond day 3 . Observed frequencies for light precipitation over the ocean are lower than over the land. Heavy precipitation ( $\mathrm{OHFH}$, bottom-right panel) is forecast to occur more often over sea points than it does over land; it is overforecast, especially over the oceans, while over land the observed frequencies are only slightly smaller.

Figure $9 \mathrm{~b}$ also shows that there are fewer misses over the ocean (panels above the diagonal), but more false alarms (ODFL, ODFH). A main component of the overall error is ODFL (middle row, left panel), referred to as "overprediction of drizzle" in Rodwell et al. (2010), that is more pronounced over the ocean. OHFL, heavy rain being underforecast as drizzle (middle row, right panel) is also a large component of the total error, more so over land than sea. ODFH error differences (bottom left) appear to suggest that land points are 
(a)

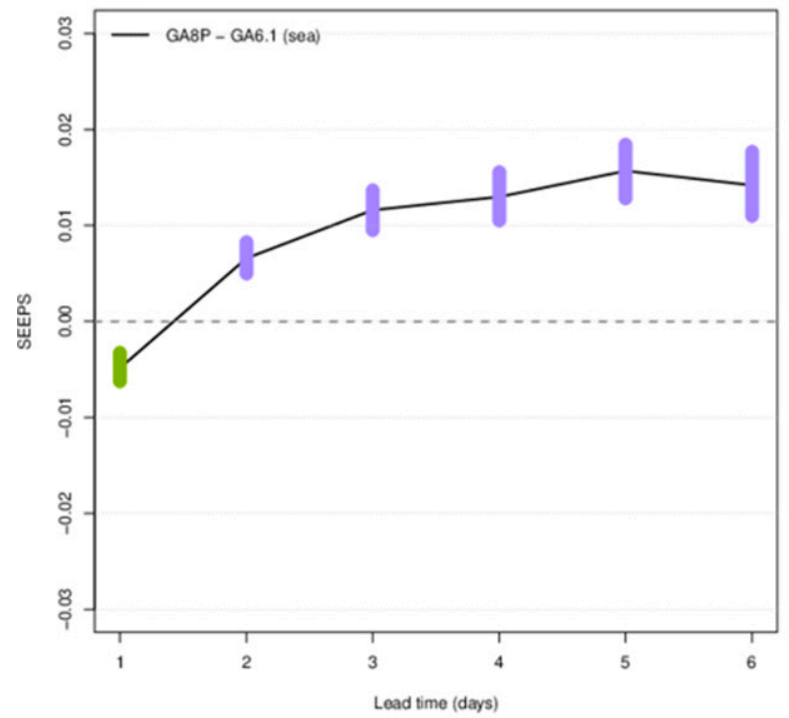

(c)
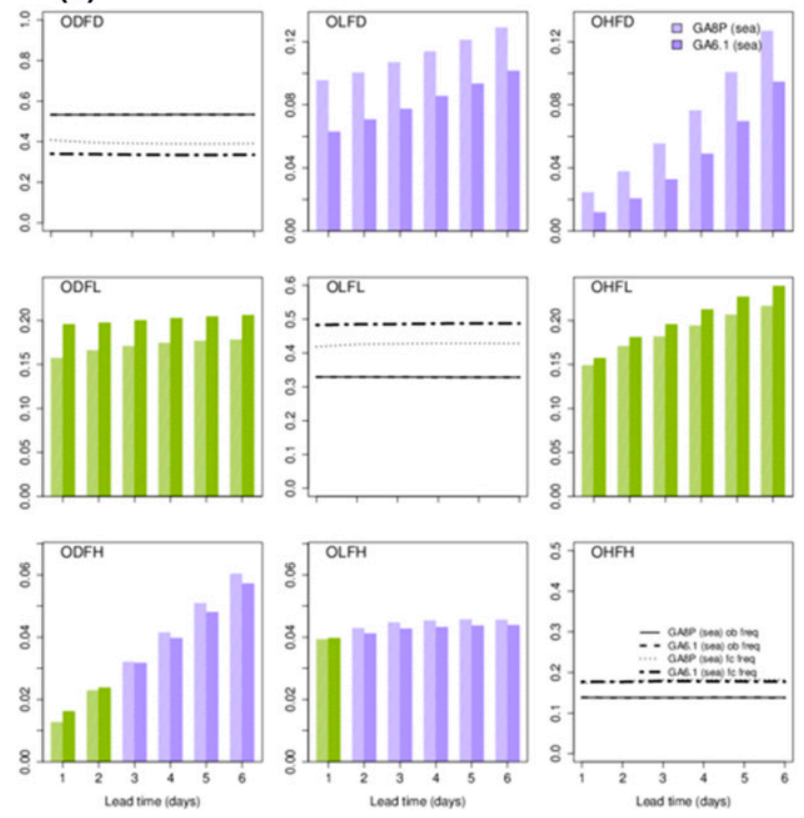

FIG. 8. Globally aggregated SEEPS difference and decomposition for the period August 2018-February 2019 for the GA8P and GA6.1 configurations as a function of lead time, split between land and sea areas: (a) aggregated sea only, (b) aggregated over all eligible land points, (c) decomposition of (a), and (d) decomposition of (b). For (c) and (d), observed dry, light, and heavy categories vary by column and those same forecast categories vary by rows. SEEPS error components are plotted in the off-diagonal panels as bars, with GA8P lightly colored and GA6.1 darker. Bars are colored in green or purple if GA8P is respectively better or worse than GA6.1 with significant differences (otherwise they would be black). Diagonal panels [from top left to bottom right in (c) and (d)] plot the observed frequencies for GA8P (solid) and GA6.1 (dashed) and forecast frequency for GA8P (dotted) and GA6.1 (dot-dashed). Unlike in Rodwell et al. (2010) a bootstrap method was used to compute $95 \%$ confidence intervals of paired SEEPS differences, with 1000 samples.

significantly better; there are less heavy category false alarms over land than over the sea, especially at longer lead times. This could be due to better modeling of the diurnal cycle of convection over land than over the sea. The miss categories (OLFD, OHFD, and OHFL) appear to have a lead-time dependence, especially over the sea. (b)

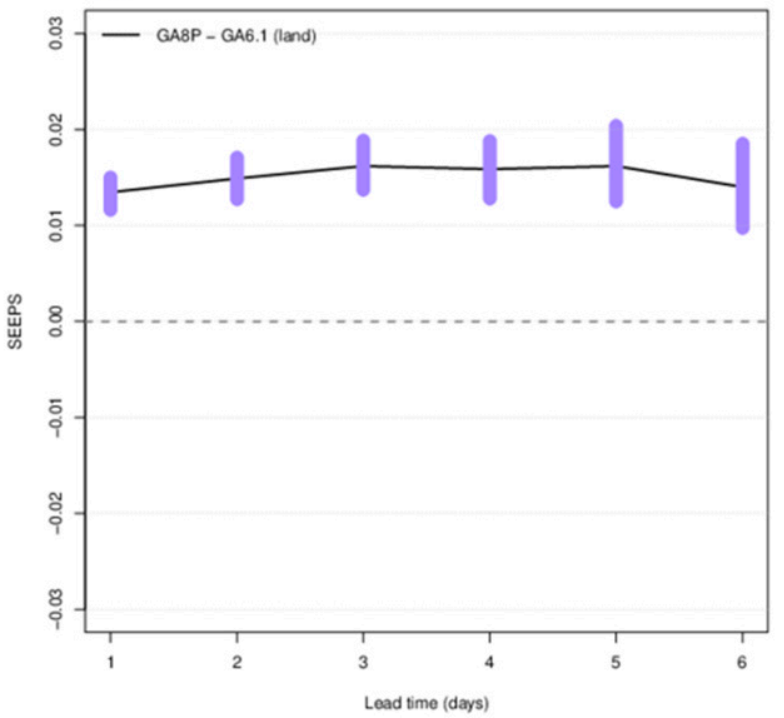

(d)
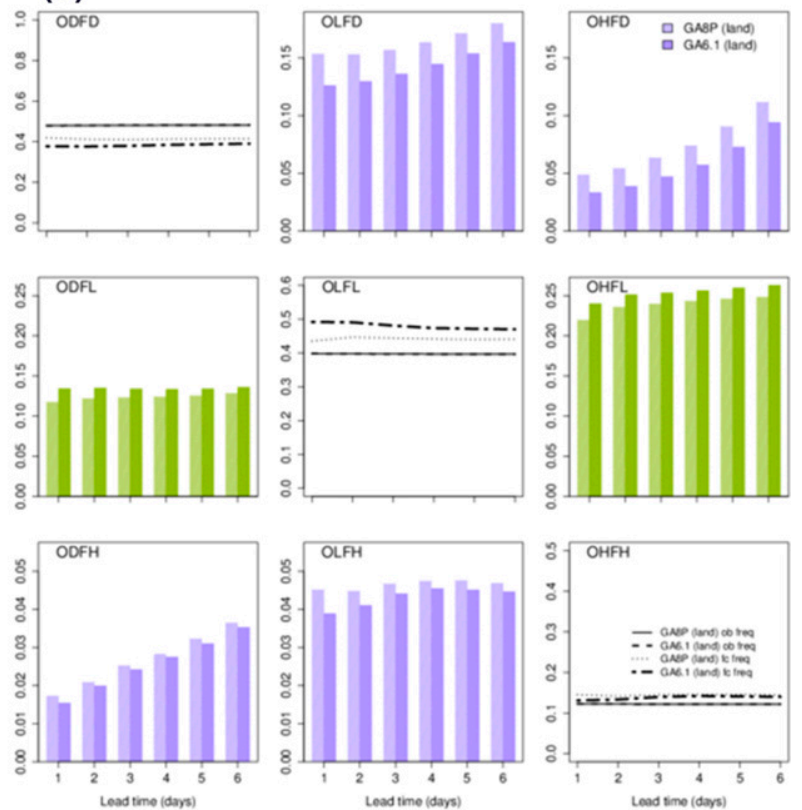
(a)

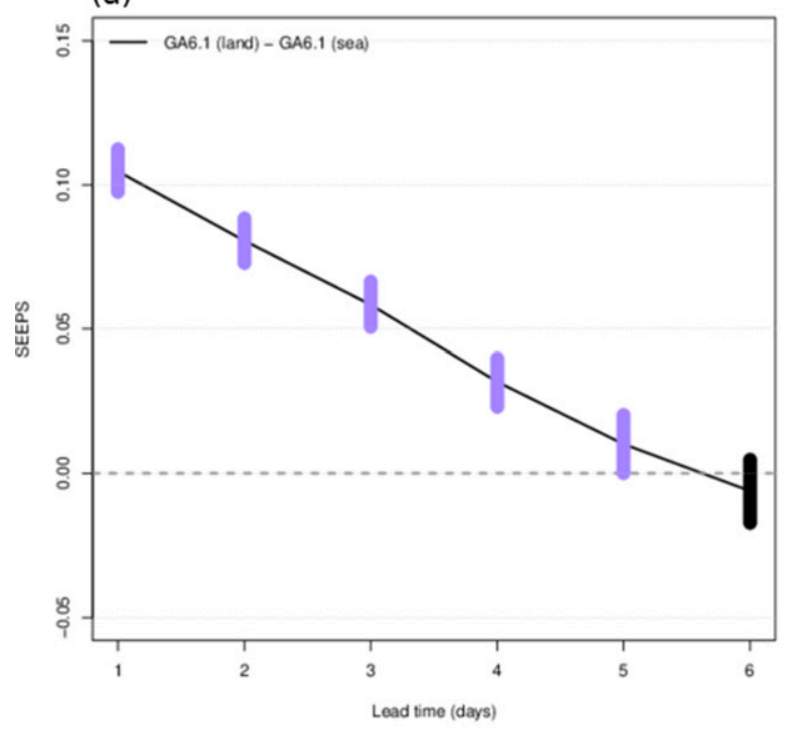

(b)
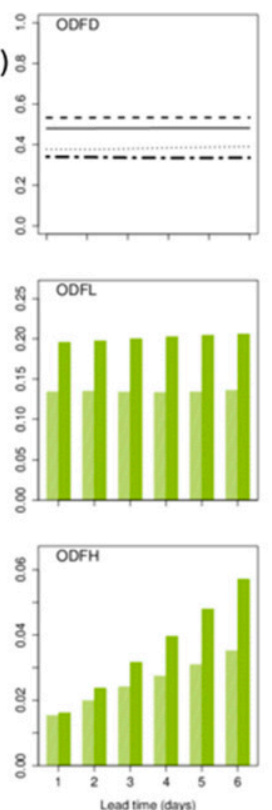
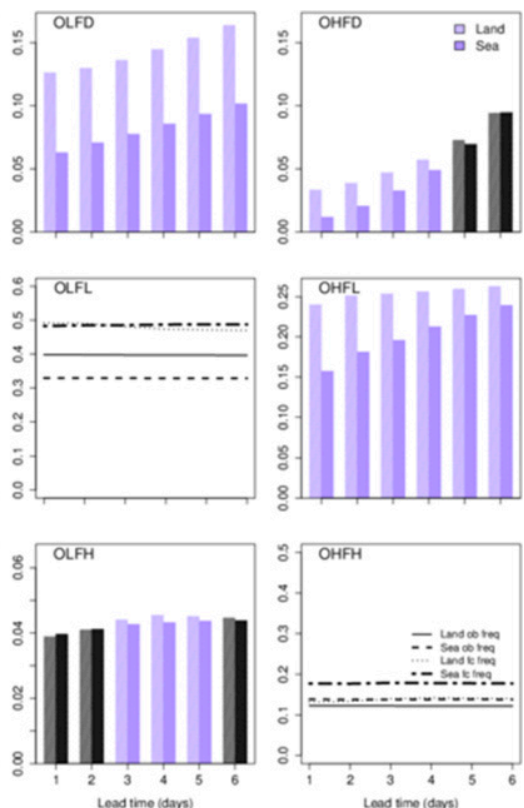

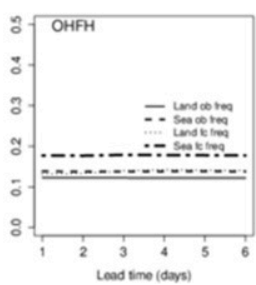

FIG. 9. (a) Comparison of global SEEPS differences for GA6.1 computed for land points and for sea only. (b) A decomposition of (a). Green or purple is associated with better performance over the land or ocean, respectively. Bars with light shading correspond to land, whereas those with dark shading correspond to ocean. Gray or black bars indicate no significant difference between GA6.1 over land or sea, respectively. The diagonal panels in (b), from top left to bottom right, show the frequencies seen at the observed land (solid), observed sea (dashed), forecast land (dotted), and forecast sea (dot-dashed) points.

differences in the score resulting from using two different observation datasets: a gauge network versus a gridded satellite product. Two comparisons are presented that explore the impact of geographical sampling (the whole domain vs the gauge locations) and representativeness (the gauge point value vs the GPM/ TRMM area-averaged value for the collocated grid point).

Using the TRMM climatology increases the sampling considerably, by two orders of magnitude, with TRMM coverage consisting of 576000 grid points as compared with the $\sim 6000$ gauge locations, which are also only over land. Equalizing the sampling results in Fig. 10a, i.e., only use the subsample of grid points containing gauges (referred to as GPM@gauge). This highlights the difference between the gridded satellite observations and the gauge point observations, which includes, and is possibly dominated by, the point-to-grid representativeness error. On the other hand, it is important to check whether the sample of grid points that contain gauges is representative of the total "population" of land-based grid points available. Figure 10b shows score differences calculated using all land points in comparison with grid points containing gauges (GPM@gauge), to show how representative the scores for this subset, of gauge locations, are of the performance over land in general. Only results for GA6.1 are shown here.

Figure 10a shows that globally, scores based on the TRMM-derived climatology are worse at early lead times but better at longer lead times. An area-average value will be less sensitive to location errors than a point measurement. At long lead times, forecast errors are likely to be location errors. For the score decomposition, the diagonal panels in Fig. 10c show a change in frequency of occurrence between the two climatologies, which provides some insights into shifts in the categories that points fall into, depending on which climatology is used; that is, there is a bias that is introduced by the observations. The gauges (dashed) have a larger dry count. The GPM@gauges (solid) have a larger drizzle frequency. The gauges also have a larger frequency of heavy precipitation. These are all expected results, related to the point location versus gridbox representativeness. The decomposition of errors in Fig. 10c is generally more positive for GPM@gauge than Fig. 10a suggests, even at earlier lead times, though compensating errors means that the early lead times end up being poorer (and significantly so) overall. GPM@gauge errors are smaller in the FL categories, but the absolute magnitude of the errors are big; the OHFL category is the largest component to the total SEEPS. The ODFH errors are better at all lead times for the GPM@gauge subset with a strong trend, suggestive of a bias, possibly in the forecast, but certainly between the observation sources, primarily as a result of representativeness capabilities of the two contrasting observation types; heavy rain that does not fall directly above a rain gauge is missed by the point observation and the model is penalized for this. On the other hand, this is captured in an area mean. The OHFD category is slightly worse or neutral for GPM@gauge at early lead times. This category is more indicative of a model bias, and this result suggests that there is a lead-time dependence in the amount of heavy precipitation the model produces. The OLFD category is significantly worse in GPM@gauge and dominates the aggregated score. 
(a)

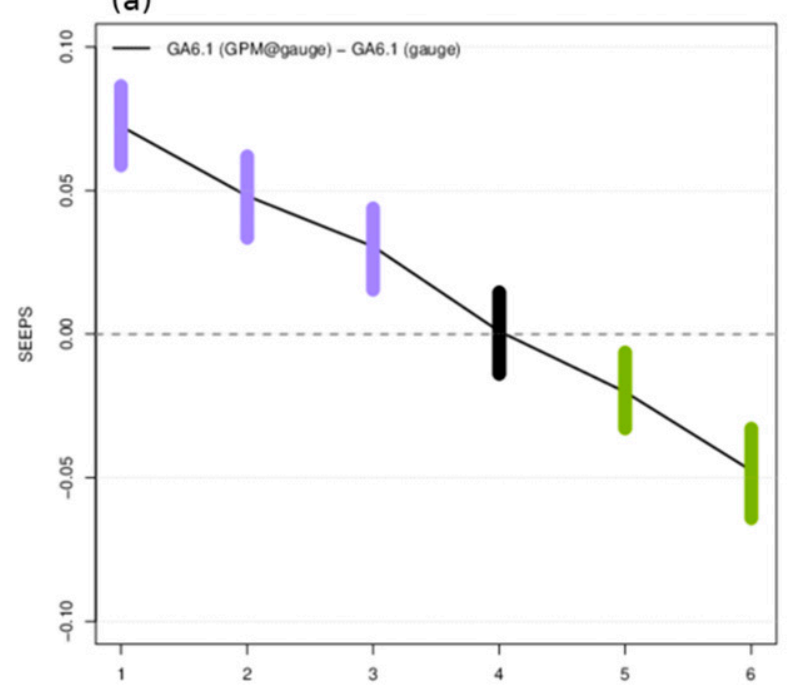

(c)
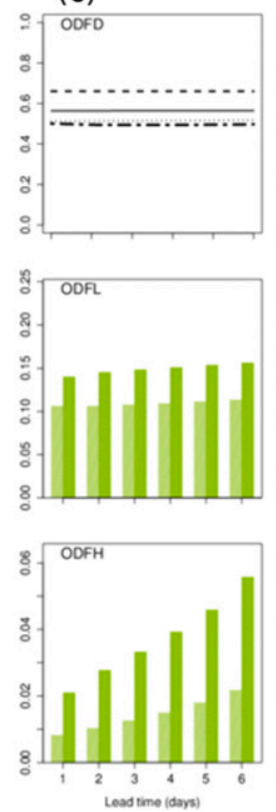

Lead time (days)
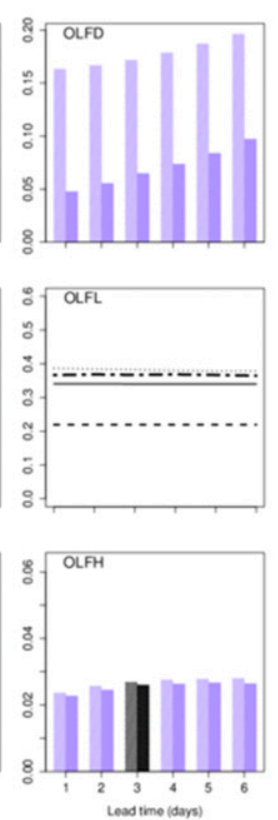
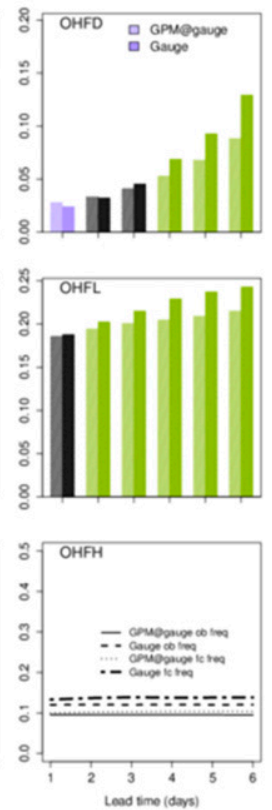

(b)

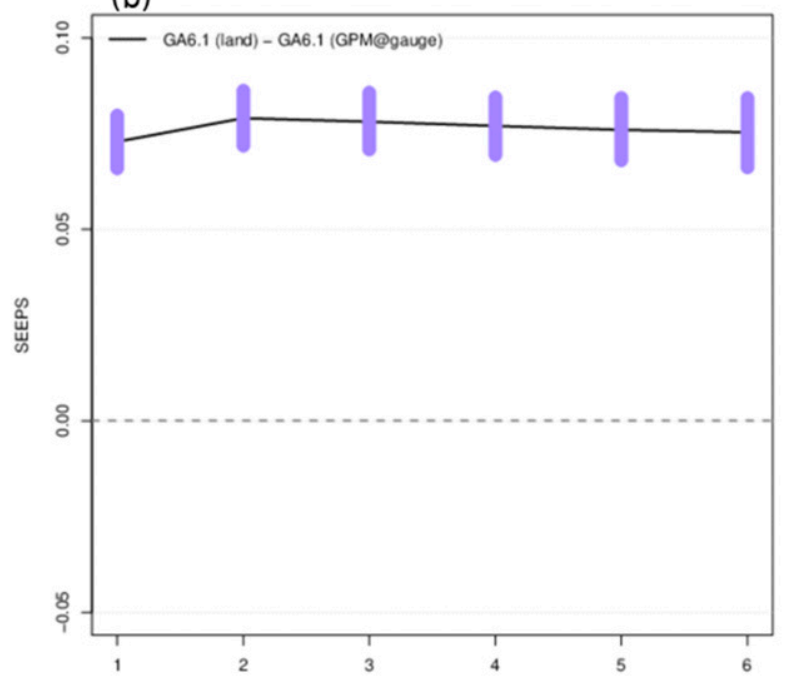

(d)
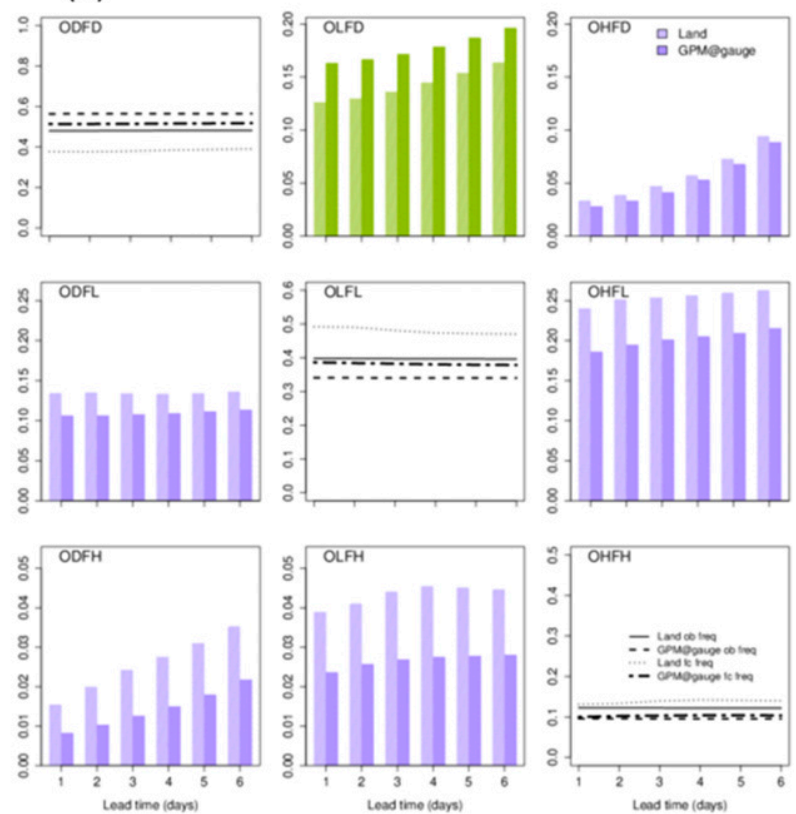

FIG. 10. Comparison of global SEEPS differences for GA6.1 (a) computed using gauges and for TRMM grid points collocated with gauge locations (GPM@gauge) and (b) computed using all land points from the satellite-derived data and for those grid points at the gauge station locations (GPM@gauge), (c) a decomposition of (a), and (d) a decomposition of (b). For (a) and (c), green or purple is associated with better performance in the satellite-derived or gauge-derived scores, respectively. In (b) and (d), green or purple respectively indicates better performance across all land points or at station locations. Black indicates no significant difference on all plots. The diagonal panels, from top left to bottom right, in (c) show the category frequencies for GPM@gauge observations (solid), gauge observations (dashed), GPM@gauge forecasts (dotted), and gauge forecasts (dot-dashed). In (d), they show the category frequencies for all land observations (solid), GPM@gauge observations (dashed), all land forecasts (dotted), and GPM@gauge forecasts (dot-dashed).

Investigating how representative the subset of TRMM land points collocated with gauges is of all possible land points, Fig. 10b suggests the subset is not very representative, with SEEPS computed over all land points worse at all lead times. Models have been tuned in the past decades to perform better based on verification results carried out at gauge locations. In addition, forecasts are "anchored" to assimilated observations, usually more dense in populated areas. More remote and difficult orography is generally not as well represented, which means that any model assessment of precipitation against gauges is not that representative of model performance in these types of remote locations. 
(a)

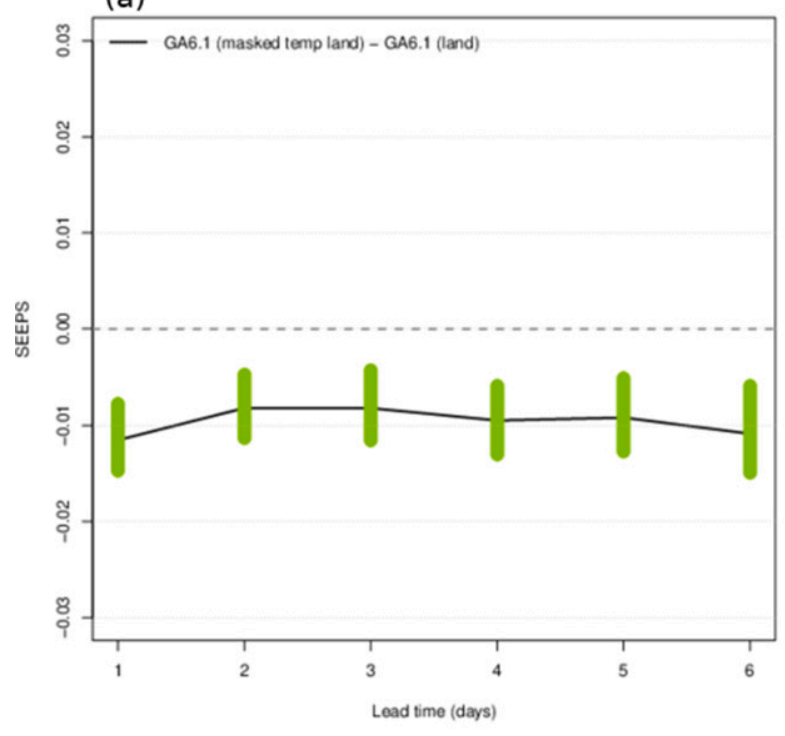

(b)
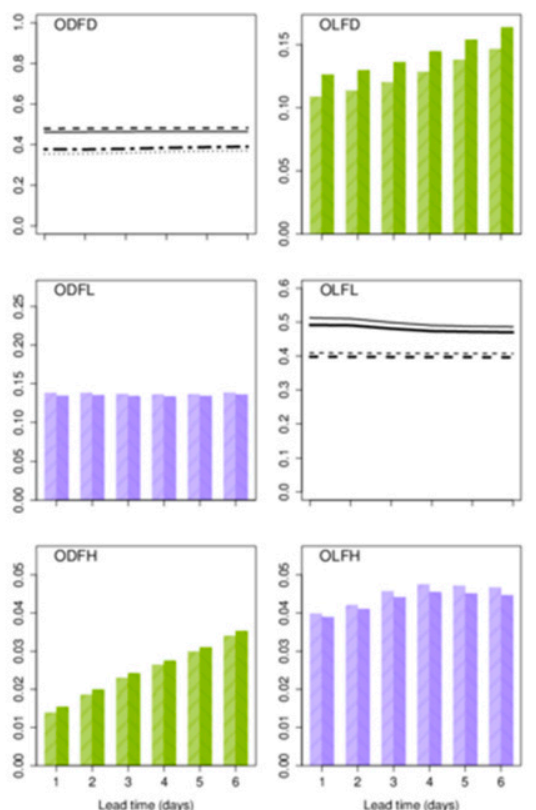
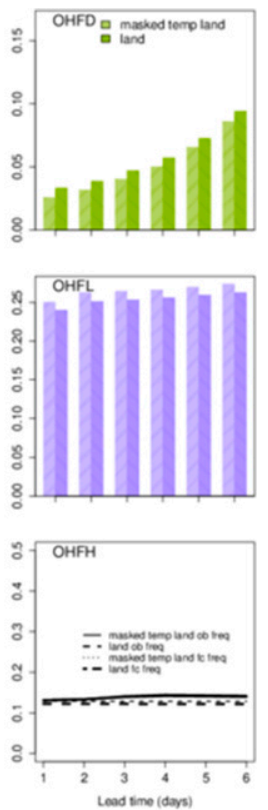

FIG. 11. (a) Differences calculated between GA6.1 over TRMM land points (excluding those with frozen surfaces and elevations over $4500 \mathrm{~m}$ as well as those due to $p_{1}$ limits) and GA6.1 using all TRMM land points (only masking points outside the recommended $p_{1}$ limits) for globally aggregated SEEPS score differences. (b) A decomposition of (a). Green or purple is associated with better performance with grid points masked where surface temperature is below zero and height is over $4500 \mathrm{~m}$ in addition to the $p_{1}$ masking or just $p_{1}$ masked, respectively. The diagonal panels (from top left to bottom right) indicate the frequencies for each category from the observations with extra points masked (solid), observations at all land points (dashed), forecasts with extra points masked (dotted) and forecasts at all land points (dot-dashed).

Though TRMM and GPM show some biases (e.g., lack of detection, especially of light rain) over extreme high ground and complex terrain, this more complete sampling of the land areas suggests that precipitation forecast performance is worse than the limited, nonrandom sampling provided by gauge locations suggests.

The diagonal panels in Fig. 10d have a frequency difference in both observations and forecasts (i.e., the sample is not representative of the population). There are more dry days in the subset than overall and more dry forecast points in the subset than overall. This is more-or-less compensated for in the light category, which has higher frequencies for land points than does the subset for both forecasts and observations. In the heavy category there are slightly more forecast points overall than in the subset, with some variations with lead time, again hinting at a leadtime-dependent forecast bias. To conclude, it would suggest that heavy precipitation locations are underrepresented in this subset of points defined by the gauge locations. This is again not that surprising given the lack of gauges in locations that could be associated with orographically persistent precipitation.

Considering the error components, Fig. 10d shows it is only the OLFD category where the score for land points does better than the subset, suggesting the lack of light precipitation in the forecast is less of an issue overall. All other error categories imply that the errors for all land points are worse, and significantly so; the largest SEEPS components are for the FL category suggesting over all land points, light precipitation forecasts are worse than for the subset representing gauge locations. OHFL contributes the largest proportion to the total SEEPS. This again hints at the point versus area-average representativeness issues. The OHFD and ODFH off-by-2 errors are worse for all land points too. This is likely to be due to the representation and placement of heavy convective precipitation in the model. The fact that the model may overestimate precipitation totals is captured in the OLFH error, indicating overall there are more instances of heavy precipitation (heavy false alarm) than in the subset sampling gauge locations only.

The observation types provide score differences (Fig. 10a) that are of the same order of magnitude as the differences between the two model configurations (Figs. 8a,c). Understanding the differences between the observation types is therefore important and should feature in the interpretation of any results. When presented with such a spread of results it is may be difficult to determine what to believe. As stated before, measuring and estimating precipitation is difficult, and using any observation for verification comes with considerable observation error contributions that are largely unquantified or unquantifiable. In section $3 \mathrm{a}$ it was noted that two of sources of uncertainty in TRMM and GPM related to subzero temperatures and higher mountains. To investigate the possible contribution of these two error sources, the $p_{1}$ masking constraints were strengthened to also remove grid points above $4500 \mathrm{~m}$ (where TRMM and GPM have detection issues) and grid points below freezing from the score aggregate.

Figure 11 shows the change in the aggregated land-only SEEPS over the whole period resulting from this additional 

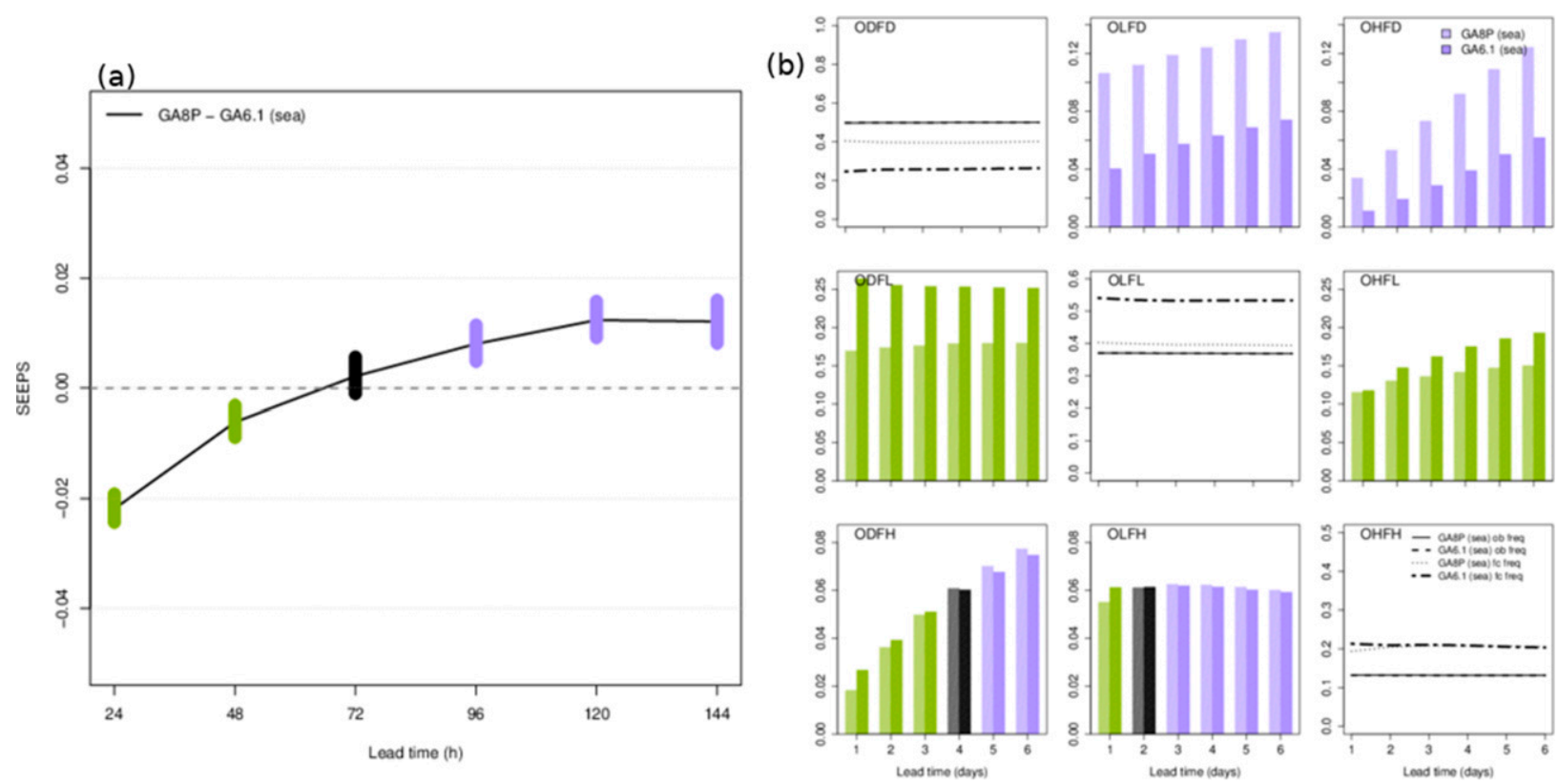

FIG. 12. (a) Difference between aggregated SEEPS scores from sea points in the tropics for GA8P and GA6.1. (b) The corresponding decomposition plot showing where the improvements originate. Observed categories (dry, light, and heavy) vary by column; forecast categories (dry, light, heavy) vary by row. Light shading indicates GA8P over the sea. Dark shading indicates GA6.1 over the sea. Green or purple is respectively associated with better performance for GA8P over the sea or GA6.1 over the sea. Black indicates no significant difference on all plots. The diagonal panels (from top left to bottom right) show the frequencies associated with GA8P observation sea points (solid), GA6.1 observation sea points (dashed), GA8P forecast sea points (dotted), and GA6.1 forecast sea points (dot-dashed).

masking to test the sensitivity of the aggregated score to locations where the observations are known to be deficient. Figure 11a shows that SEEPS, when globally aggregated over all land points, improves with the removal of these points. Figure 1b shows where the improvements come from. Improvements are seen in the missed categories (OLFD and OHFD), possibly because of points being removed that are below freezing, thus incorrectly identified as precipitating (Massari and Maggioni 2020). There is also improvement in the heavy false alarm category, presumably due to points being removed that have a likelihood of the observation having detection issues.

\section{c. Regional SEEPS}

While the use of the climatologies makes it possible to aggregate SEEPS globally, arguably there is greater interest in understanding regional signals. Rodwell et al. (2010) and Haiden et al. (2012) also aggregated SEEPS over smaller focused geographical areas. To investigate whether signals seen in Figs. 8-10 could be linked to a specific region, SEEPS were aggregated over two regions: (i) the tropics, since this is traditionally where model error is very large, with few gauges and large expanses of ocean, and (ii) North America, since there are a large number of gauge stations here so a more robust comparison of the gauge versus TRMM derived scores can be performed. Continental convection is also an interesting weather regime to consider from a spatial sampling and representativeness point of view.

\section{1) TROPICS}

Figure 12a shows the SEEPS differences between GA8P and GA6.1 based on sea points only in the tropics, defined to be between $20^{\circ} \mathrm{N}$ and $20^{\circ} \mathrm{S}$ [as per the definition in World Meteorological Organization (2019)]. This shows a benefit from GA8P at early lead times, but only until day 3 .

Decomposition of SEEPS in Fig. 12b indicates GA8P has higher frequencies of dry events over the sea than GA6.1 (top left). This increase is offset by a reduced frequency of light rain. These signals indicate improvements in GA8P relative to GA6.1. The bias that has been commented on previously for heavy events is again evident over sea points in the tropics.

In looking at error categories in the off-diagonal panels, it is seen that benefit from GA8P is mainly in the ODFL category (a reduction in false alarms). There is also benefit in the OHFL category (misses). This indicates that GA8P gains in discrimination. FH categories contribute minimally to the error, and with mixed signals. However, misses are in greater numbers for GA8P (FD, top row) supporting the idea that too much precipitation has been removed. Note that these results from Fig. 12 align with those found globally over the ocean (Figs. 8a,c).

\section{2) NORTH AMERICA}

North America is a good region over which to test whether there are differences between the TRMM-derived and gauge- 
(a)

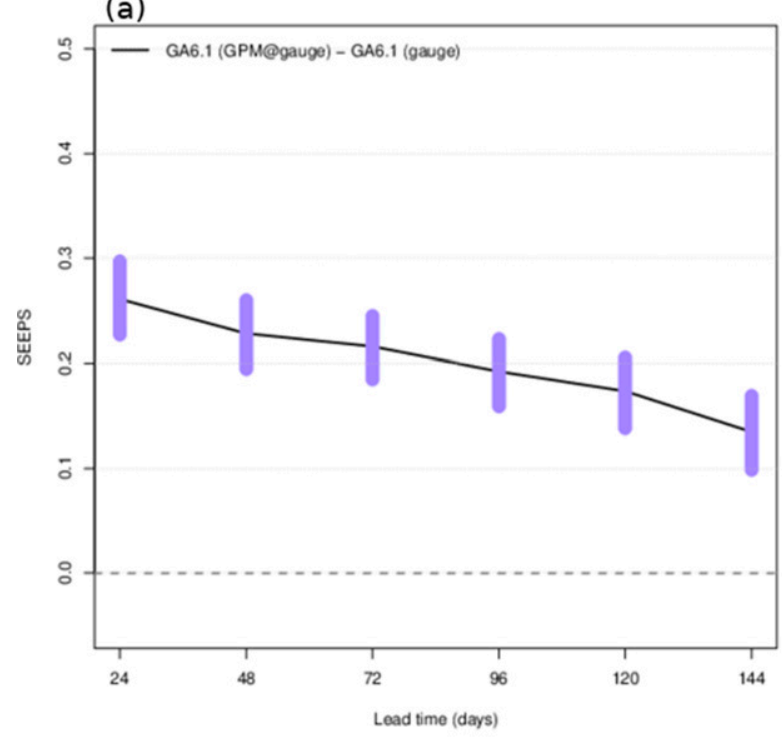

(b)
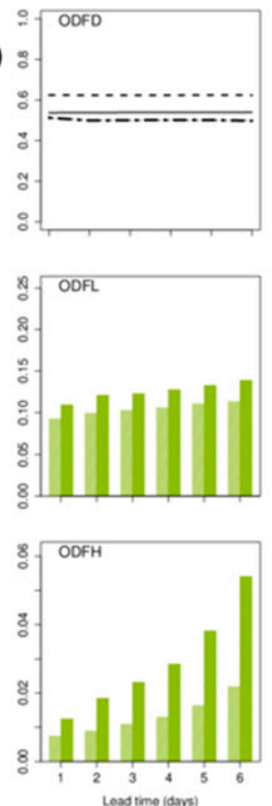
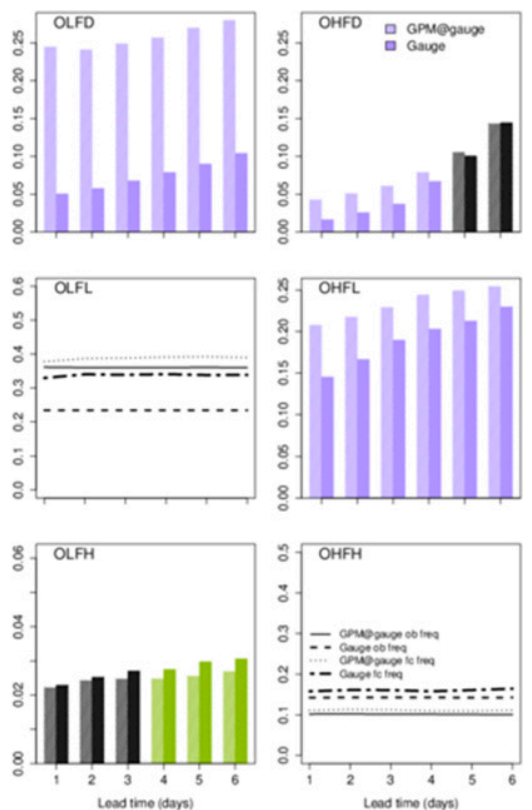

FIG. 13. (a) Difference between aggregated SEEPS from the TRMM-derived climatology at gauge locations in GA6.1 and GA6.1 gauge-derived scores over North America. (b) The corresponding decomposition plot. Observed categories (dry, light, heavy) vary by column; forecast categories (dry, light, heavy) vary by row. Green or purple is associated with better performance from satellite-derived scores or gauge-derived scores, respectively, at station locations. Black indicates no significant differences. On the diagonal (from top left to bottom right) the frequencies are plotted for GPM@gauge observations (solid), gauge observations (dash), GPM@gauge forecasts (dotted), and gauge forecasts (dot-dashed).

derived SEEPS (both determined at gauge locations) because of increased gauge density there.

Figure 13a shows that GPM@gauge SEEPS is generally worse than the gauge SEEPS, with the difference decreasing with lead time. SEEPS components in Fig. 13b show no significant differences in dry forecast frequencies and more dry events in the gauges with respect to TRMM/GPM. This could be because gauges are not capturing the rain unless falling directly on the gauge location. On the other hand, the middle panel (OLFL) shows overestimation of light precipitation from TRMM/GPM (relative to gauges), which suggests that gridded products tend to enhance the drizzle. The forecast frequencies for light and heavy rain are different, suggesting that the forecast upscaling to the TRMM coarser resolution has resulted in a change in the light-to-heavy event frequencies (this occurs also for the global results, in Fig. 10c for the category $\mathrm{OHFH}$ ). Heavy frequencies are higher for the gauge climatology than for TRMM, as in Fig. 10c, again possibly related to a representativeness issue.

GPM@gauge errors in Fig. 13b are smaller in some categories, but these differences are smaller in magnitude and thus not reflected in the total SEEPS. It is interesting to note that for GPM there are fewer false alarms (better for categories below the diagonal) while for gauges there are fewer misses so that score components are better for categories above the diagonal.

Fewer false alarms may arise because of a better match of area-mean precipitation in the model to the gridded satellite data; also the forecast heavy precipitation may be less likely to be penalized for not being detected by a gauge (ODFH). Misses may relate to the differences in the dry-light-heavy rain boundaries between climatologies (though at longer lead times the differences are not significant for the OHFD category). The OHFL category is the second-largest component of the total SEEPS, but the difference between scores derived from the different climatologies is small. However, the OLFD difference is far larger than any of the others and dominates the overall error. These suggest that there is a difference in the sampling of light rain and in the light-heavy threshold between gauges and TRMM/GPM, which strongly affect the verification results.

Given that a substantial part of the study period was during the boreal winter and known issues of light rain detection in subzero temperatures and over higher mountainous terrain such as the Rockies affect the satellite products, the identification and elimination of grid locations with enhanced observation uncertainties is recommended. Note that the results seen in Fig. 13b mostly align with those seen globally in Fig. 10c. There are differences in the observed heavy errors (OHFD, OHFL) and the heavy false alarms (OLFH).

\section{Conclusions}

In this study we have introduced the use of SEEPS with GPM and a satellite-based TRMM climatology for the verification of NWP forecasts of daily precipitation. The climatology was derived from the $25-\mathrm{km}$ resolution TRMM TMPA 3B42 (V7) research product, while the daily accumulations 
for verification are provided by the 10-km-resolution GPM grid product. The advantage of deriving the climatology from a gridded data source is that SEEPS can be calculated over the whole spatial domain. This means precipitation verification with SEEPS can be presented over the sea for the first time. We first compared two versions of the Met Office Unified Model (GA8P and GA6.1), globally and considering the land and sea area separately, over the entire TRMM coverage. Then we showed verification results for two regional subdomains.

The tropics were chosen because of there being few gauges, with a large proportion of sea points, and it being where we expect to see differences from the physics changes in the models. North America was selected because of the large number of gauges sited over land, to compare the gauge-derived and TRMM-derived scores.

All comparisons were carried out on the $25-\mathrm{km}$ grid of the climatology. We have also compared the satellite-based verification results with those obtained from traditional gauge observations. GA8P moves some light precipitation into the dry category, reducing the overforecasting of drizzle error (ODFL) but increases the number of missed drizzle events (OLFD). Over the ocean the major difference between the two configurations are found in the forecast dry errors (OLFD, OHFD in Figs. 8c and 12b).

In general, the gauge and satellite climatologies compare well on a spatial map, given the inherent differences in their representativeness. We see that the light-heavy threshold is more likely to be higher in the TRMM climatology at locations where the threshold is less than $100 \mathrm{~mm} \mathrm{day}^{-1}$. Variations in the gauge versus TRMM climatologies are seen mostly over land, off the northern Australian coast and in the vicinity of the Pacific Islands (Figs. 2 and 5), which result in differences in the score behavior when SEEPS is evaluated against gauges versus GPM/TRMM; this suggests that representativeness is still a key issue in verification. As an example, gauges tend to have a higher frequency of dry events, whereas GPM/TRMM has a higher frequency of light precipitation (Figs. 10 and 13, diagonal). This arises because of gauges missing precipitation unless exactly where the precipitation falls, whereas gridded products suffer from trace overestimation (some local precipitation is "spread" and smoothed over the grid box). As a result, we diagnose larger frequencies of false alarms (ODFL and ODFH) for the gauges and see a larger number of misses (OLFD) when verifying against satellite products, as in Figs. 10c and 13b.

Using a gridded product to evaluate a gridded model forecast may alleviate this effect. However, understanding the uncertainties and sources of the differences between gauges and gridded observation datasets requires more work. At the very least some effort is needed to investigate further whether differences are due to stations strongly affected by representativeness issues associated with local effects, or whether they are due to error characteristics of the satellite product. We have shown (Fig. 11) that removing the points where known biases affect the quality of the satellite product can improve SEEPS. Being able to interpret results where the same forecast verified against different observation sources provides different results remains a considerable dilemma. Ways in which the observational uncertainties are incorporated into the presentation of forecast verification results should be considered a high priority activity in general, noting that the SEEPS results here are not the only scenario where these differences and issues arise.

Daily and monthly aggregated SEEPS can be mapped to show the spatial patterns of the error (Figs. 6 and 7). The appropriate time scale over which to average depends on the phenomenon of interest. We have shown that systematic spatial patterns of forecast errors are set up early, within day 1. Uncommonly large SEEPS are prevalent at the edges of dry ocean regions west of landmasses (increasingly with lead time). SEEPS over land are larger than over the oceans.

Also, it has been shown that the time-aggregated SEEPS and their contributing error categories can be mapped to highlight differences in behavior between model configurations, in this case on monthly and seasonal time scales.

When comparing the gauge-derived and TRMM/GPM-derived SEEPS there should be no expectation that they are the same. The study period has illustrated clearly that different observation types may produce score differences of the same order of magnitude as the difference between the model configurations. We have shown that the subset of TRMM points collocated with gauges is not representative of all land points as measured by TRMM/GPM. This should not come as a surprise given that gauges are geographically inhomogeneously distributed, with large swathes of land not sampled at all or in a very limited capacity. Using the TRMM climatology offers a spatially smooth and consistent means of assessing precipitation forecast skill.

In looking ahead, it is seen that high-resolution modeling also means considering subdaily accumulations and the diurnal cycle. Breaking GPM and TRMM down to shorter accumulations is possible, but some of the biases and limitations of the product are exacerbated for shorter accumulation lengths. Nevertheless, 6- $h$ accumulations are feasible and remains the logical next step. The sensitivity of the score to the dry/light threshold in the satellite-derived climatology needs to be investigated, due to the uncertainty in the detection of light rain. In addition, recently the GPM IMERG product has been made available back into the TRMM era. The intention is to derive a climatology using this new source and to investigate if there are differences. These climatologies will then be used for ongoing monitoring of NWP skill using SEEPS and TRMM/GPM, supplementing the current method using SEEPS calculated with the gauge-derived climatologies. These observed gridded products can also be used to identify gauges that are strongly influenced by local effects, ensuring that they are not used in NWP verification but are retained for analyzing representativeness error and have postprocessing applied. SEEPS error categories, aggregated on appropriate time scales, can be used to assess modeling of particular precipitation phenomenon in case studies. Aggregated areamean scores can be used to highlight improvements in particular meteorological regimes.

The creation of subdaily climatologies is also a possibility if local gridded climatologies are available for a sufficiently long enough period. These could replace GPM/TRMM or supplement gauge-derived point climatologies. However, it remains 
true that the GPM/TRMM datasets are an attractive option for obtaining a consistent precipitation dataset over many regions where there is very little else available.

Acknowledgments. The authors thank two anonymous referees and Barbara Casati for their insightful comments, which have helped to improve the paper.

Data availability statement. Met Office Unified Model operational global model data are available from the Met Office on request. Model output from the trial configuration will only be available for a period of two years because of the data-archiving policy for nonoperational models. The SEEPS gauge climatology was constructed using SYNOP observations exchanged on the WMO Global Telecommunications System and was provided to the Met Office by ECMWF. Contact ECMWF directly to inquire about availability. The TRMM (TMPA) Rainfall Estimate L3 3-h $0.25^{\circ} \times 0.25^{\circ} \mathrm{V7}$ data were provided by the NASA/Goddard Space Flight Center's Mesoscale Atmospheric Processes Laboratory and PPS, which develop and compute the 3B42 V7 product as a contribution to TRMM, and are archived at the NASA GES DC (https://doi.org/10.5067/TRMM/TMPA/3H/7). The GPM IMERG Final V06B data were provided by the NASA/Goddard Space Flight Center's Global Precipitation Measurement mission team and PPS, which develop and compute the IMERG Final V06B product as a contribution to GPM, and are archived at the NASA GES DISC (https://doi.org/10. 5067/GPM/IMERG/3B-HH/06).

\section{REFERENCES}

Bharti, V., and C. Singh, 2015: Evaluation of error in TRMM 3B42V7 precipitation estimates over the Himalayan region. $J$. Geophys. Res. Atmos., 120, 12458-12473, https://doi.org/10. 1002/2015JD023779.

Cecinati, F., A. M. Moreno-Ródenas, M. A. Rico-Ramirez, M. Ten Veldhuis, and J. G. Langeveld, 2018: Considering rain gauge uncertainty using kriging for uncertain data. Atmosphere, 9, 446, https://doi.org/10.3390/atmos9110446.

Chen, S., and Coauthors, 2015: Intercomparison of precipitation estimates from WSR-88D radar and TRMM measurement over continental United States. IEEE Trans. Geosci. Remote Sens., 53, 4444-4456, https://doi.org/10. 1109/TGRS.2015.2399307.

Chen, Y., E. E. Ebert, K. J. Walsh, and N. E. Davidson, 2013: Evaluation of TRMM 3B42 precipitation estimates of tropical cyclone rainfall using PACRAIN data. J. Geophys. Res. Atmos., 118, 2184-2196, https://doi.org/10.1002/jgrd.50250.

Ciach, G. J., 2003: Local random errors in tipping-bucket rain gauge measurements. J. Atmos. Oceanic Technol., 20, 752759, https://doi.org/10.1175/1520-0426(2003)20<752:LREITB> 2.0.CO;2.

Clayton, A. M., A. C. Lorenc, and D. M. Barker, 2012: Operational implementation of a hybrid ensemble/4D-Var global data assimilation system at the Met Office. Quart. J. Roy. Meteor. Soc., 139, 1445-1461, https://doi.org/10.1002/qj.2054.

Climate Prediction Center, 2020: Madden/Julian Oscillation update archive. NOAA Center for Weather and Climate
Prediction, accessed October 2020, https://www.cpc.ncep. noaa.gov/products/precip/CWlink/MJO/ARCHIVE/PDF/.

Cui, W., X. Dong, B. Xi, Z. Feng, and J. Fan, 2020: Can the GPM IMERG final product accurately represent MCSs' precipitation characteristics over the central and eastern United States? J. Hydrometeor., 21, 39-57, https://doi.org/10.1175/ JHM-D-19-0123.1.

Ebert, E. E., J. E. Janowiak, and C. Kidd, 2007: Comparison of near-real-time precipitation estimates from satellite observations and numerical models. Bull. Amer. Meteor. Soc., 88, 47-64, https://doi.org/10.1175/BAMS-88-1-47.

ECMWF, 2015: Precipitation climatology to facilitate computation of the SEEPS score. European Centre for Medium Range Weather Forecasts, accessed 2015, https://confluence.ecmwf. int/display/WLD/Climatology.

Edwards, J. M., and A. Slingo, 1996: Studies with a flexible new radiation code. I: Choosing a configuration for a large scale model. Quart. J. Roy. Meteor. Soc., 122, 689-719, https://doi. org/10.1002/qj.49712253107.

Gandin, L. S., and A. H. Murphy, 1992: Equitable skill scores for categorical forecasts. Mon. Wea. Rev., 120, 361-370, https:// doi.org/10.1175/1520-0493(1992)120<0361:ESSFCF > 2.0.CO;2.

Gregory, D., and P. Rowntree, 1990: A mass flux convection scheme with representation of cloud ensemble characteristics and stability-dependent closure. Mon. Wea. Rev., 118, 1483-1506, https://doi.org/10.1175/1520-0493(1990)118<1483: AMFCSW $>2.0 . \mathrm{CO} ; 2$.

Habib, E., W. F. Krajewski, V. Nespor, and A. Kruger, 1999: Numerical simulation studies of rain gage data correction due to wind effect. J. Geophys. Res., 104, 19 723-19733, https:// doi.org/10.1029/1999JD900228.

Haiden, T., M. Rodwell, D. Richardson, A. Okagaki, T. Robinson, and T. Hewson, 2012: Intercomparison of global model precipitation forecast skill in 2010/11 using the SEEPS score. Mon. Wea. Rev., 140, 2720-2733, https://doi.org/10.1175/ MWR-D-11-00301.1.

Hamill, T., and J. Juras, 2006: Measuring forecast skill: Is it real skill or is it varying climatology? Quart. J. Roy. Meteor. Soc., 132, 2905-2923, https://doi.org/10.1256/qj.06.25.

Hou, A. Y., and Coauthors, 2014: The global precipitation measurement mission. Bull. Amer. Meteor. Soc., 95, 701-722, https://doi.org/10.1175/BAMS-D-13-00164.1.

Huffman, G. J., R. F. Adler, M. M. Morrissey, D. T. Bolvin, S. Curtis, R. Joyce, B. McGavock, and J. Susskind, 2001: Global precipitation at one-degree daily resolution from multisatellite observations. J. Hydrometeor., 2, 36-50, https://doi.org/10. 1175/1525-7541(2001)002<0036:GPAODD > 2.0.CO;2.

- - D. D. B. Bolvin, and E. J. Nelkin, 2010: The TRMM Multi-Satellite Precipitation Analysis (TMPA). Satellite Rainfall Applications for Surface Hydrology, M. Gebremichael and F. Hossain, Eds., Springer, 3-22, https://doi.org/10.1007/ 978-90-481-2915-7_1.

Humphrey, M. D., J. D. Istok, J. Y. Lee, J. A. Hevesi, and A. L. Flint, 1997: A new method for automated dynamic calibration of tipping-bucket rain gauges. J. Atmos. Oceanic Technol., 14, 1513-1519, https://doi.org/10.1175/1520-0426(1997) 014<1513:ANMFAD > 2.0.CO;2.

Køltzow, M., B. Casati, E. Bazile, T. Haiden, and T. Valkonen, 2019: An NWP model intercomparison of surface weather parameters in the European Arctic during the Year of Polar Prediction Special Observing Period Northern Hemisphere 1. Wea. Forecasting, 34, 959-983, https://doi.org/10.1175/WAFD-19-0003.1. 
Kummerow, C., and Coauthors, 2000: The status of the Tropical Rainfall Measuring Mission (TRMM) after two years in orbit. J. Appl. Meteor., 39, 1965-1982, https://doi.org/10.1175/15200450(2001)040<1965:TSOTTR > 2.0.CO;2.

Lock, A., A. Brown, M. Bush, G. Martin, and R. Smith, 2000: A new boundary layer mixing scheme. Part 1: Scheme description and single column model tests. Mon. Wea. Rev., 128, 3187-3199, https://doi.org/10.1175/1520-0493(2000)128<3187: ANBLMS $>2.0 . \mathrm{CO} ; 2$.

Maggioni, V., P. Meyers, and M. Robinson, 2016: A review of merged high-resolution satellite precipitation product accuracy during the Tropical Rainfall Measuring Mission (TRMM) era. J. Hydrometeor., 17, 1101-1117, https://doi.org/ 10.1175/JHM-D-15-0190.1.

Mass, C., D. Ovens, K. Westrick, and B. Colle, 2002: Does increasing horizontal resolution produce more skillful forecasts? The results of two years of real-time numerical weather prediction over the Pacific northwest. Bull. Amer. Meteor. Soc., 83, 407-430, https://doi.org/10.1175/1520-0477(2002)083<0407: DIHRPM $>2$ 2.3.CO;2.

Massari, C., and V. Maggioni, 2020: Error and uncertainty characterization. Satellite Precipitation Measurement, Vol. 2, V. Levizzani et al., Eds., Springer, 515-532, https://doi.org/10.1007/ 978-3-030-35798-6_4.

Murphy, A., and R. Winkler, 1987: A general framework for forecast verification. Mon. Wea. Rev., 115, 1330-1338, https://doi. org/10.1175/1520-0493(1987)115<1330:AGFFFV>2.0.CO;2.

North, R., M. Trueman, M. Mittermaier, and M. Rodwell, 2013: An assessment of the SEEPS and SEDI metrics for the verification of $6 \mathrm{~h}$ forecast precipitation accumulations. Meteor. Appl., 20, 164-175, https://doi.org/10.1002/met.1405.

O, S., U. Foelsche, G. Kirchengast, J. Fuchsberger, J. Tan, and W. A. Petersen, 2017: Evaluation of GPM IMERG Early, Late, and Final rainfall estimates using WegenerNet gauge data in southeastern Austria. Hydrol. Earth Syst. Sci., 21, 6559-6572, https://doi.org/10.5194/hess-21-6559-2017.

Peirce, C., 1884: The numerical measure of the success of predictions. Science, NS-4, 453-454, https://doi.org/10.1126/science. ns-4.93.453.b.

Roca, R., P. Chambon, I. Jobard, P.-E. Kirstetter, M. Gosset, and J. C. Bergès, 2010: Comparing satellite and surface rainfall products over West Africa at meteorologically relevant scales during the AMMA campaign using error estimates. J. Appl. Meteor. Climatol., 49, 715-731, https://doi.org/10.1175/2009 JAMC2318.1.

Rodwell, M., D. Richardson, T. Hewson, and T. Haiden, 2010: A new equitable score suitable for verifying precipitation in numerical weather prediction. Quart. J. Roy. Meteor. Soc., 136, 1344-1363, https://doi.org/10.1002/qj.656.

- , T. Haiden, and D. Richardson, 2011: Developments in precipitation verification. ECMWF Newsletter, No. 128, ECMWF, Reading, United Kingdom, 12-16, https://www.ecmwf.int/node/ 14595.

Rossa, A., P. Nurmi, and E. Ebert, 2008: Overview of methods for the verification of quantitative precipitation forecasts. Precipitation: Advances in Measurement, Estimation and Prediction, S. Michaelides, Ed., Springer, 419-452, https://doi.org/10. 1007/978-3-540-77655-0_16.
Skofronick-Jackson, G., and Coauthors, 2017: The Global Precipitation Measurement (GPM) mission for science and society. Bull. Amer. Meteor. Soc., 98, 1679-1695, https://doi.org/10. 1175/BAMS-D-15-00306.1.

Smalley, M., T. L'Ecuyer, M. Lebsock, and J. Haynes, 2014: A comparison of precipitation occurrence from the NCEP Stage IV QPE product and the CloudSat Cloud Profiling Radar. J. Hydrometeor., 15, 444-458, https://doi.org/10.1175/JHM-D-13048.1.

TRMM, 2011: TRMM (TMPA) Rainfall Estimate L3 3 hour 0.25 degree $\times 0.25$ degree V7. Goddard Earth Sciences Data and Information Services Center (GES DISC), accessed 2015, https://doi.org/10.5067/TRMM/TMPA/3H/7.

Villarini, G., P. V. Mandapaka, W. F. Krajewski, and R. J. Moore, 2008: Rainfall and sampling uncertainties: A rain gauge perspective. J. Geophys. Res., 113, D11102, https://doi.org/10. 1029/2007JD009214.

Vogel, P., P. Knippertz, A. H. Fink, A. Schlueter, and T. Gneiting, 2018: Skill of global raw and postprocessed ensemble predictions of rainfall over northern tropical Africa. Wea. Forecasting, 33, 369-388, https://doi.org/10.1175/WAF-D-17-0127.1.

Walters, D., and Coauthors, 2017: The Met Office Unified Model Global Atmosphere 6.0/6.1 and JULES Global Land 6.0/6.1 configurations. Geosci. Model Dev., 10, 1487-1520, https://doi. org/10.5194/gmd-10-1487-2017.

Willett, M., and M. Whitall, 2017: A simple prognostic based convective entrainment rate for the unified model: Description and tests. Met Office Forecasting Research Tech. Rep. 617, 54 pp., https:/digital.nmla.metoffice.gov.uk/download/file/digital File_2add1f55-d638-4120-97ce-69bf57cc5916.

Wilson, D., and S. Ballard, 1999: A microphysically based precipitation scheme for the UK Meteorological Office Unified Model. Quart. J. Roy. Meteor. Soc., 125, 1607-1636, https:// doi.org/10.1002/qj.49712555707.

- A. Bushell, A. Kerr-Munslow, J. Price, and C. Morcrette, 2008: PC2: A prognostic cloud fraction and condensation scheme. I: Scheme description. Quart. J. Roy. Meteor. Soc., 134, 2093-2107, https://doi.org/10.1002/qj.333.

Wood, N., and Coauthors, 2013: An inherently mass-conserving semi-implicit semi-Lagrangian discretization of the deepatmosphere global non-hydrostatic equations. Quart. J. Roy. Meteor. Soc., 140, 1505-1520, https://doi.org/10.1002/qj.2235.

World Meteorological Organization, 2019: Manual on the Global Data-processing and Forecasting System: Annex IV to the WMO Technical Regulations. WMO Doc. WMO-485, 148 pp., https://library.wmo.int/doc_num.php?explnum_id=10164.

Xu, R., F. Tian, L. Yang, H. Hu, H. Lu, and A. Hou, 2017: Ground validation of GPM IMERG and TRMM 3B42V7 rainfall products over southern Tibetan Plateau based on a high-density rain gauge network. J. Geophys. Res. Atmos., 122, 910-924, https://doi.org/10.1002/2016JD025418.

Yang, S., and S. W. Nesbitt, 2014: Statistical properties of precipitation as observed by the TRMM precipitation radar. Geophys. Res. Lett., 41, 5636-5643, https://doi.org/10.1002/ 2014GL060683.

Zhang, S., D. Wang, Z. Qin, Y. Zheng, and J. Guo, 2018: Assessment of the GPM and TRMM precipitation products using the rain gauge network over the Tibetan Plateau. J. Meteor. Res., 32, 324-336, https://doi.org/10.1007/s13351-018-7067-0. 